[Type text]

\title{
A minimalist functional group (MFG) approach for surrogate fuel formulation
}

Abdul Gani Abdul Jameel ${ }^{\mathrm{a}}$, Nimal Naser ${ }^{a}$, Gani Issayev ${ }^{a}$, Jamal Touitou ${ }^{b}$, Manik Kumer Ghosh ${ }^{b}$, AbdulHamid Emwas ${ }^{c}$, Aamir Farooq ${ }^{a}$, Stephen Dooley ${ }^{b}$, S. Mani Sarathy ${ }^{{ }^{*}}$

${ }^{a}$ King Abdullah University of Science and Technology (KAUST), Clean Combustion Research Center (CCRC), Thuwal 23955-6900, Saudi Arabia

${ }^{b}$ School of Physics, Trinity College Dublin, Dublin, Ireland

'King Abdullah University of Science and Technology, Imaging and Characterization Core Laboratory, Thuwal23955-6900, Saudi Arabia

*Corresponding author:

S. Mani Sarathy mani.sarathy@kaust.edu.sa

Abdul Gani Abdul Jameel abdulgani.abduljameel@kaust.edu.sa

\section{Abstract}

Surrogate fuel formulation has drawn significant interest due to its relevance towards understanding combustion properties of complex fuel mixtures. In this work, we present a novel approach for surrogate fuel formulation by matching target fuel functional groups, while minimizing the number of surrogate species. Five key functional groups; paraffinic $\mathrm{CH}_{3}$, paraffinic $\mathrm{CH}_{2}$, paraffinic $\mathrm{CH}$, naphthenic $\mathrm{CH}-\mathrm{CH}_{2}$ and aromatic $\mathrm{C}-\mathrm{CH}$ groups in addition to structural information provided by the Branching Index (BI) were chosen as matching targets. Surrogates were developed for six FACE (Fuels for Advanced Combustion Engines) gasoline target fuels, namely FACE A, C, F, G, I and J. The five functional groups present in the fuels were qualitatively and quantitatively identified using high resolution ${ }^{1} \mathrm{H}$ Nuclear Magnetic Resonance (NMR) spectroscopy. A further constraint was imposed in limiting the number of surrogate components to a maximum of two. This simplifies the process of surrogate formulation, facilitates surrogate testing, and significantly reduces the size and time involved in developing chemical kinetic models by reducing the number of thermochemical and kinetic parameters requiring estimation. Fewer species also reduces the computational expenses involved in simulating combustion in practical devices. The proposed surrogate formulation methodology is denoted as the Minimalist Functional Group (MFG) approach. The MFG surrogates were experimentally tested against their target fuels using Ignition Delay Times (IDT) measured in an Ignition Quality Tester (IQT), as specified by the standard ASTM D6890 methodology, and in a Rapid Compression Machine 
[Type text]

(RCM). Threshold Sooting Index (TSI) and Smoke Point (SP) measurements were also performed to determine the sooting propensities of the surrogates and target fuels. The results showed that MFG surrogates were able to reproduce the aforementioned combustion properties of the target FACE gasolines across a wide range of conditions. The present MFG approach supports existing literature demonstrating that key functional groups are responsible for the occurrence of complex combustion properties. The functional group approach offers a method of understanding the combustion properties of complex mixtures in a manner which is independent, yet complementary, to detailed chemical kinetic models. The MFG approach may be readily extended to formulate surrogates for other complex fuels.

Keywords: surrogate; functional group; ${ }^{1} \mathrm{H}$ NMR spectroscopy; ignition delay time (IDT); rapid compression machine (RCM); threshold sooting index (TSI); virtual smoke point

\section{INTRODUCTION}

Transportation fuels, such as gasoline [1] and diesel [2] are complex hydrocarbon mixtures containing hundreds to thousands of individual molecules. Identifying and quantifying all of these molecules is challenging, which complicates modeling of their combustion behavior. Therefore, surrogate fuels (usually mixtures of two or more pure components) are formulated to mimic one or more of the target fuel's physical and chemical properties (e.g., density, average molecular weight, distillation characteristics, viscosity, surface tension, $\mathrm{H} / \mathrm{C}$ ratio, heat of combustion etc.) and combustion properties (e.g., laminar flame speed, sooting tendencies, pollutant formation, etc.). This facilitates creating detailed chemical kinetic models of fuel surrogates needed to simulate, design and optimize the combustion in the engine. Surrogate fuels are also useful in developing standardized mixtures for reproducible experiments. These can be easily prepared with knowledge of the composition of the pure components present therein, thus enabling the possibility of experimental repeatability in different locations without the complications posed by fuel variability.

There has been significant research carried out to develop suitable surrogates for gasoline [3-12], diesel [13-17], jet fuel [18-23], biodiesel [24-28], and even heavy fuel oils [29]. One of the common approaches in formulating surrogates for gasolines is to match the chemical 
reactivity of the target fuel at certain standard conditions with primary reference fuels (PRFs), i.e., mixtures of iso-octane (2,2,4-trimethylpentane) and n-heptane [30]. The ignition delay data measured in a Co-operative Fuel Research (CFR) engine is utilized to measure the antiknock quality of the fuel (i.e., research and motor octane numbers). The composition of the PRF that matches the knocking characteristics of the target fuel, as specified by the ASTM methodologies such as ASTM D2699-15a [31] for Research Octane Number (RON) and ASTM D2700-16 [32] for Motor Octane Number (MON), are specified as the surrogates.

Apart from antiknock quality, other constraints like the physical and chemical properties of the target fuel may also be matched depending upon the type of engine application. Hydrogen/Carbon $(\mathrm{H} / \mathrm{C})$ ratio of the fuel, which is necessary to calculate the fuel/air ratio, significantly determines the amount of heat released during combustion. It also dictates the amount of carbon dioxide and water formed. Though $\mathrm{H} / \mathrm{C}$ ratio is a global value, it helps shed light on the molecular diversity of the fuel, as it is the result of relative content of paraffins, aromatics, naphthenes and olefins. Aromatic rings have $\mathrm{H} / \mathrm{C}$ close to unity, while paraffins having $\mathrm{H} / \mathrm{C}$ closer to 2 . The $\mathrm{H} / \mathrm{C}$ also constrains the identity and population of the radical pool, which has been suggested to be the fundamental driver for the occurrence of phenomena which are strongly chemical kinetic in nature, such as induction time, flame velocity and diffusive extinction limits [23]. It has been shown that the average molecular weight of the fuel is a useful measure to regulate the rate of fuel diffusion in the gas phase [33], which is important in many transport dominated combustion processes. The transport weighted enthalpy [34] can be matched by matching the fuel's enthalpy of combustion and the average molecular weight of the fuel; the former property depends on the total bond dissociation energy contained in distinct functional groups. The average carbon number of molecules observed in gasolines is around 7 , and a mismatch could result in loss of fidelity in reproducing the combustion kinetic behavior. The Derived Cetane Number (DCN) is calculated from the IDT measured in an IQT; it helps to relate the ignition quality of a fuel with its molecular structure [23]. The $\mathrm{H} / \mathrm{C}$ ratio and DCN are important constraints in controlling the kinetic behavior. Other parameters, such as functional groups (collections of atoms giving distinct chemically reacting behaviors), carbon types, threshold sooting index (TSI), density, distillation curve, etc. have also been used as targets in 
[Type text]

developing surrogates. Surrogate fuel formulation strategies and the necessary fuel property targets have been discussed in detail $[1,8,18,21,22,35]$.

This study presents a new methodology to develop fuel surrogates by matching a group of molecular fragments or "functional groups" that are readily identifiable and quantifiable in the target fuel by NMR, while at the same time minimizing the number of surrogate molecules used to match the functional groups. The methodology is hence denoted as the MFG approach. We hypothesize that the functional group distribution serves as an indicator of distinctly reacting chemical functionalities, which are finite arrangements of several adjacent functional groups that govern chemical reactivity. For example, it is well known that trimethylene, $-\mathrm{CH}_{2} \mathrm{CH}_{2} \mathrm{CH}_{2}$ - is a limiting chemical functionality for the occurrence of low temperature alkylperoxy radical isomerization leading to chain-branching. In practical fuels, this chemical functionality can be difficult to identify by NMR spectroscopy, but the constituent $\mathrm{CH}_{2}$ functional group is easily quantifiable and gives a clear indication of the presence of the larger functionality.

Previous surrogate fuel formulation approaches $[3,18,21,22,35,36]$ matched the hydrocarbon class distribution by including many species from different classes in the surrogate. Violi et al. [37] used up to 6 components in their surrogate for JP-8 aviation fuel. The surrogate components were selected based on the broad hydrocarbon classes (paraffins, iso-paraffins, naphthenes, aromatics) in the fuel. The existence of chemical mechanisms for the species was also used as a criteria for component selection. This work is novel because we focus on matching functional groups (i.e. the objective function) making up these hydrocarbon classes, which is a more fundamental approach. We also demonstrate that as little as one or two molecules can be used to match the fuel functional groups to formulate surrogates of practical gasoline fuels.

It is accepted that a surrogate with more components can do a better job in replicating fuel behavior. The recent surrogates formulations [21,23,35,37-39] reported in the literature generally tend to increase the complexity of the surrogate by adding more species, which has made the entire process of surrogate formulation cumbersome and expensive. We show that simple surrogates when formulated with knowledge of a fuels functional groups can do a nearequal job as more complex surrogates. Five functional groups; $\mathrm{CH}_{3}$, paraffinic $\mathrm{CH}_{2}$, paraffinic $\mathrm{CH}$, 
naphthenic $\mathrm{CH}-\mathrm{CH}_{2}$ and aromatic $\mathrm{C}-\mathrm{CH}$ were selected to describe the series of standard gasoline fuels used as candidates to test the approach. Gasolines are mostly composed of four molecular classes (namely n-paraffins and iso-paraffins, olefins, naphthenes and aromatic), and, initially, an attempt was made to design a single average molecule that could match all the functionalities in the fuel. However, such designer molecules are not commercially available and/or are too expensive to be synthesized. Thus in the present work in order to have surrogates molecules that could be procured for experimental testing, this attempt was abandoned. Therefore, our MFG approach permitted a maximum of two molecules to match the functional groups in the target fuel. The FACE gasoline fuels [40] serve as good standard set of target fuels for developing and testing surrogate fuel formulation strategies. FACE gasolines are specifically designed fuels with consistent physical and chemical properties to meet the needs of data reproducibility in research applications. Surrogates were developed for six FACE gasolines, namely FACE A, C, F, G, I and J, and experiments were performed to test the MFG approach.

\section{BACKGROUND}

A functional group can be defined as any portion of a molecule composed of a group of atoms, which governs both its physical and chemical properties and chemical reactivity. Practical fuels, such as gasoline, comprise a large number of hydrocarbon molecules, which in turn contain a limited number of functional groups. It is these functional groups that mostly determine the combustion kinetic properties of the practical fuel [29]. The quantity and type of functional groups present in a compound also determine their physical properties (e.g., density [41], viscosity [41]), thermochemical properties (e.g., heat capacity [42], heat of formation [43], critical properties, etc.) and various combustion properties (e.g., flash point, cetane number, flame speed, etc. $[44,45])$. There is a strong correlation between the composition of different functional groups and the physical and chemical behavior of the fuel $[16,17,21]$.

Recently Abdul Jameel et al. [46] used six functional groups, namely paraffinic $\mathrm{CH}_{3}$, paraffinic $\mathrm{CH}_{2}$, paraffinic $\mathrm{CH}$, olefinic $\mathrm{CH}-\mathrm{CH}_{2}$, naphthenic $\mathrm{CH}-\mathrm{CH}_{2}$, and aromatic $\mathrm{C}-\mathrm{CH}$ and a new Branching Index (BI) parameter to predict the DCN of hydrocarbon fuels. Dooley et al. [23] studied jet fuel surrogates by disassembling the surrogate molecules into three molecular groups; $\mathrm{CH}_{3}, \mathrm{CH}_{2}$ and 
$\mathrm{C}_{6} \mathrm{H}_{3} \mathrm{X}_{2} \mathrm{CH}_{2}$ (benzyl type), and found that the proportions of these groups in the fuel govern radical pool formation which defines the combustion behavior. It was found that, irrespective of the parent surrogate molecule, these molecular building blocks play a major role controlling chemical reactions. The $\mathrm{CH}_{3}$ and $\mathrm{CH}_{2}$ groups are the most common building blocks of (paraffinic) hydrocarbon fuels and Won et al. [47] have shown that the $\mathrm{CH}_{2} / \mathrm{CH}_{3}$ ratio by the metric $\frac{\mathrm{CH}_{2}}{\mathrm{CH}_{3}} *$ $\left(\mathrm{CH}_{2}+\mathrm{CH}_{3}\right)$ can define the reactivity of low temperature alkylperoxy radicals in paraffinic fuels. $\mathrm{CH}_{2} / \mathrm{CH}_{3}$ ratio also governs the ignition delay of $n$-paraffin fuels in the boiling range of diesel fuels $[48,49]$. Though shown to be very constraining information, clearly the simple $\mathrm{CH}_{2} / \mathrm{CH}_{3}$ molecular structure metric of Won et al. [47] is inadequate to differentiate the different combustion kinetic behaviors that are due to the isomeric arrangement of the fragments comprising such molecules. Here, it is well known that both the degree of branching (methylation) and position of the branching in the molecule are defining contributors to the combustion reactivity of the fuel. See for example the heptane isomers [50]. In order to consider this fundamental issue in surrogate formulations by functional group replications, we have previously introduced the Branching Index parameter, which considers both the degree of branching, and the position of the branching in the hydrocarbon [46].

The functional group additivity approach has been used for estimating the reaction rates by using the alkyl and free radical groups [51]. Sumathi et al. [52-54] predicted the reaction rates for a number of reaction sets used in kinetic models by extending Benson's group additivity tables. Pepiot-Desjardin et al. [55] used group additivity to predict the sooting tendencies of various fuels. Yang et al. [38] used the basic compositional data of jet fuels to predict the TSI in gas turbine combustors. Mehl et al. [56] defined fuel surrogates for high molecular weight compounds by using pseudo components that contain the functional groups present in the target fuel. The functional group based lumping techniques employed by Ranzi et al. $[57,58]$ at the CRECK modeling group in POLIMI replaced the long polymer chains with monomer pseudo species that participate in different reactions like initiation and abstraction. The developed model was able to successfully predict the thermo-gravimetric data. Lumping techniques have also been used to simulate the hydrocracking of petroleum hydrocarbon mixtures [59]. Structural group contribution methods have been proposed to predict the smoke point of pure hydrocarbons [60] 
and to interpret the sooting tendency of hydrocarbon fuels [55]. It has also been experimentally shown that different functional groups result in different sooting behaviors [61].

When different types of functional groups are chosen, such that they contain most of the structural information of the target fuel, additional properties are likely to be matched, such as thermochemical properties, intermediate species formation, and the radical pool. Recently Yu et al. [62] formulated a surrogate mixture for biodiesel comprising methyl-9-decenoate, 1,4dihexadiene and $n$-dodecane considering four functional groups such as $-\mathrm{CH}_{3},-\mathrm{CH}_{2},-\mathrm{CH}-\mathrm{CH}=\mathrm{CH}$ and $-\mathrm{COO}-\mathrm{CH}_{3}$. Five functional groups, i.e., $\mathrm{CH}_{3}, \mathrm{CH}_{2}, \mathrm{CH}, \mathrm{C}$ and phenyl, have been used to generate surrogate mixtures for jet fuels [62]. Won et al. [39] have demonstrated that the combustion performance of complex fuels can be reproduced by formulating surrogates based on four combustion property targets namely $\mathrm{H} / \mathrm{C}$ ratio, TSI, average molecular weight and DCN. These targets, which were used for surrogate emulation of aviation kerosene fuels, effectively constrained the functional group distribution seen in the fuel. Therefore, it is evident that functional groups can be used as a target property in developing surrogates for practical fuels, in order to reproduce important combustion phenomenon. Indeed, the chemical structure of the fuel is the fundamental defining feature.

In the present work, we formulate surrogates for gasoline fuels using a minimal number of species, so as to unambiguously test the functional group principle. In doing so, the number of species and reactions required for detailed chemical kinetic models will also be reduced, thus making realistic combustion simulations with detailed chemistry more viable. Gasoline surrogate mixtures currently presented in the literature perform reasonably well in matching the selected properties of target gasolines, but their application to practical engine simulations has been limited. One major concern is that developing accurate detailed chemical kinetic models for many surrogate species is difficult, as it requires many experiments and theoretical calculations. Furthermore, detailed chemical kinetic models for gasoline surrogates contain thousands of species and reactions, which requires enormous computational expenses when performing simulations. For example, Lawrence Livermore National Laboratory's detailed kinetic model for a four component RD-387 gasoline surrogate [8] contains 1388 species and 5933 reversible 
reactions, while the detailed model for a five component surrogate by Pudupakkam et al. [63] consists of 2099 species and 9789 reactions. The FACE gasoline surrogate mechanism developed by Sarathy et al. [36] has 2406 species and 9633 reactions.

Various surrogate formulation strategies reported in the literature generally tend to add more species to match a broad range of target properties, thereby increasing the complexity of the surrogate. Binary mixtures of $n$-heptane and iso-octane (PRFs) have been specified as suitable surrogates for matching the ignition characteristics of alkane-rich FACE gasolines A and C $[2,43]$ across a range of conditions because the target fuels primarily comprise $n$ - and iso- paraffins. Bhavani Shankar et al. [30] experimentally evaluated PRFs as surrogates for four low sensitivity gasoline fuels (FACE A, C, I and J) under kinetically controlled homogenous charge compression ignition $(\mathrm{HCCl})$ conditions in a CFR engine; they found that using RON based surrogates were adequate for reproducing the heat release characteristics for low sensitivity, alkane-rich gasolines. Ternary fuel mixtures of $\mathrm{n}$-heptane, iso-octane and toluene, termed as toluene primary reference fuel (TPRF), have also been used as gasoline surrogates [64-67]. Mehl et al. [8] developed a surrogate for gasoline RD-387 containing four components (TPRF and 2-pentene) that matched the ignition behavior better than a TPRF surrogate. Naik et al. [68] proposed a five component gasoline surrogate (TPRF, 1-pentene and methylcyclohexane) by including one representative fuel from each of the chemical classes present in the target gasoline. Pudupakkam et al. [63] also developed a five component gasoline surrogate (TPRF, 1-hexene and iso-hexane) by matching several fuel properties like RON, MON, H/C ratio, lower heating value and liquid density. Recently, Ahmed et al. [3] formulated surrogates for FACE A and C gasoline by considering a palette of 6 species (TPRF, n-butane, 2-methylbutane and 2-methylhexane). The surrogate composition was chosen to match the target fuel's distillation characteristics, carbon types, RON and other physical properties. Elwardany et al. [11] developed a seven component surrogate (PRF, n-butane, iso-pentane, 3-methylhexane, 2,6-dimethyloctane and 1-methyl-2propylcyclohexane) by matching the evaporation characteristics to adequately predict fuel droplet lifetime and droplet surface temperature. Sarathy et al. $[36,69]$ formulated surrogates for four FACE gasolines (A, C, F, and G), and performed chemical kinetic modeling of the surrogates to understand the ignition characteristics of the target gasolines. FACE gasolines ( $F$ 
and $\mathrm{G}$ ) with higher aromatic and naphthenic content required surrogate mixtures with three or more components to match ignition characteristics [44]. Our present approach is novel, in that we have focused on reducing the complexity of the surrogate by reducing the number of palette species, thereby simplifying the surrogates.

Five functional groups were selected as key descriptors - paraffinic $\mathrm{CH}_{3}$, paraffinic $\mathrm{CH}_{2}$, and aromatic $\mathrm{C}-\mathrm{CH}$, as indicated by previous works [55]. In addition, we also considered paraffinic $\mathrm{CH}$, naphthenic $\mathrm{CH}-\mathrm{CH}_{2}$ groups, and the $\mathrm{BI}$ [46]. The quantity of these functional group in the FACE gasoline fuels was evaluated with high resolution ${ }^{1} \mathrm{H}$ NMR spectroscopy. Based on the type and the quantity of the functional groups present, surrogate molecules were chosen to represent these fuels. The surrogates were experimentally validated using measurements from an ignition quality tester (IQT), a rapid compression machine (RCM), and a smoke point (SP) apparatus. The derived cetane number (DCN) of the surrogates were also experimentally evaluated by using the ignition delay times (IDT) obtained from the IQT, while the threshold sooting index (TSI) was obtained from the smoke point.

\section{EXPERIMENTAL METHODS}

\subsection{Fuel Characterization}

Many analytical techniques have been used in the literature for the structural characterization of hydrocarbon fuels, including Gas Chromatography-Mass Spectrometry (GCMS) [70], Liquid Chromatography-Mass Spectroscopy (LC-MS) [71], supercritical fluid chromatography [72], Infra-Red (IR) spectroscopy [73], Raman spectroscopy [74], vibrational spectroscopy [75], Fourier Transform- Ion Cyclotron Resonance/Mass Spectrometry (FT-ICR/MS) [76,77], FT-IR spectroscopy [78,79] and Nuclear Magnetic Resonance (NMR) spectroscopy $[29,77]$. A suitable technique for quantifying the atom types in hydrocarbon fuels is ${ }^{1} \mathrm{H} N M R$ spectroscopy. The advantages of ${ }^{1} \mathrm{H}$ NMR spectroscopy are that it is reproducible, accurate, nondestructive and the molecular groups can be identified with a high resolution. The ${ }^{1} \mathrm{H}$ NMR spectra of hydrocarbon fuels can be collected in a few minutes, while conventional techniques like GC-MS are time consuming. ${ }^{1} \mathrm{H}$ NMR spectroscopy is particularly useful for high throughput experiments where a large number of samples have to be analyzed within a short period of time 
for quality control. NMR spectra are represented by chemical shifts; the number and position of these shifts is indicative of molecular structure. The various functional groups in the fuel appear as peaks at their characteristic chemical shift regions. Each functional group is assigned its own chemical shift range, and by integrating the peak in the defined region, the functional groups are quantified. One of the important advantages of NMR spectroscopy is that functional groups closely resembling each other give distinct signals, which facilitates identification and quantification.

${ }^{1} \mathrm{H}$ NMR experiments of the six FACE gasoline fuels namely FACE A, C, F, G, I and J (acquired from Chevron Philips Chemical Co) were performed and the spectra are shown in Fig. 1 . The ${ }^{1} \mathrm{H}$ NMR spectra were recorded using Bruker 700 AVANAC III spectrometer equipped with Bruker CP $\mathrm{TCl}$ multinuclear CryoProbe (BrukerBioSpin) at $298 \mathrm{~K}$. Samples were prepared by dissolving $50 \mu \mathrm{l}$ of gasoline in $700 \mu$ l of deuterated chloroform $\mathrm{CDCl}_{3} .600 \mu \mathrm{l}$ of the solution was then transferred to $5 \mathrm{~mm}$ NMR tubes after being vortexed for $30 \mathrm{~s}$. A recycle delay time of $5 \mathrm{~s}$ was used and the spectra were recorded. 128 scans were collected with standard 1D 90 pulse sequence using the standard (zg) program from Bruker pulse library. The spectra was processed using Bruker Topspin 2.1 software. Chemical shifts were adjusted using Tetramethylsilane (TMS) as an internal chemical shift reference. The spectra were collected with $20 \mathrm{ppm}$ of spectral width corresponding to $14098 \mathrm{~Hz}$, and digitized into 64k data points. An exponential function equivalent to a $0.3 \mathrm{~Hz}$ line broadening was applied before Fourier transform. The spectra were visually phased and the base lines were adjusted using abs command. The spectra were processed 5 times and the average values are reported.

\subsection{Functional group determination}

The ${ }^{1}$ H NMR structural assignments used in the present study to identify the characteristic regions of the functional groups were taken from the works of Sarpal et al. [80] and Basu et al. [81], as shown in Table 1. Functional groups were calculated from knowledge of the different hydrogen atoms present in the sample. The mole \% of a particular $\mathrm{H}$ type in the sample was calculated from the integral intensity of that region divided by the integral intensities of all the other regions, and then multiplying by 100 . The quantity of each functional group (in weight \%) 
was calculated by knowledge of the total relative number of carbons in the group and the molecular weight of the group. For example, the paraffinic $\mathrm{CH}_{3}$ group possesses three hydrogen atoms for every carbon atom. The quantity of the paraffinic $\mathrm{CH}_{3}$ group in terms of weight \% is then evaluated by multiplying the mole \% of the $\mathrm{H}$ atoms that appear in paraffinic $\mathrm{CH}_{3}$ groups (namely I and E, see Table 1) with the molecular weight (i.e., 15), and then dividing by the number of hydrogen atoms (i.e. 3) appearing in the group. Table 2 reports the formulas used for calculating the weight $\%$ of the different functional groups from the ${ }^{1} \mathrm{H}$ NMR spectra. The molecular weight of the naphthenic $\mathrm{CH}-\mathrm{CH}_{2}$ and olefinic $\mathrm{CH}=\mathrm{CH}_{2}$ groups were taken as 13.5 assuming that the hydrogen atoms are split equally between the $\mathrm{CH}$ and $\mathrm{CH}_{2}$ groups. The contribution of quaternary carbon atoms that do not show up in the ${ }^{1} \mathrm{H}$ NMR spectra were included in the aromatic $\mathrm{C}-\mathrm{CH}$ group, and were calculated by considering the $\mathrm{CH}, \mathrm{CH}_{2}$ and $\mathrm{CH}_{3}$ groups that appear in $\alpha$ position to the rings. The weight $\%$ of the functional groups was used, instead of mole \%, because mole \% values may be slightly misleading in some cases. For example, toluene (commonly observed in gasolines) is made up of one aromatic ring and one paraffinic $\mathrm{CH}_{3}$ group. The mole \% of these groups in toluene is calculated as $50 \%$ each. This attributes a lower importance to the aromatic $\mathrm{C}-\mathrm{CH}$ group despite its high molecular weight relative to the paraffinic $\mathrm{CH}_{3}$ group.

Functional groups control combustion properties across a range of conditions, but studies have shown that different isomers with the same functional groups have different cetane number and low temperature reactivity (e.g., 2-methylheptane and 3-methylheptane [82-86]) because the arrangement of functional groups differs. It is well established that the rate of low temperature oxidation is governed by the functional groups in a fuel [87]. Furthermore, the position of the functional groups, such as alkyl substitutions, influences low temperature reactivity by controlling the rate of isomerization reactions (e.g., $\mathrm{RO}=\mathrm{QOOOH}$ [39]). In $\mathrm{n}$ - and iso-paraffins, the sequence of $\mathrm{CH}_{2}$ groups governs low temperature reactivity by influencing the rate of $\mathrm{RO} 2$ and $\mathrm{O} 2 \mathrm{QOOH}$ isomerizations via 6- and 7-membered transition state rings. The introduction of alkyl substitutions hinders low temperature reactivity; both the number and position of these substitutions are important [88]. Similarly, alkyl substitutions in aromatics influence low temperature reactivity by introducing functional groups that participate in low 
[Type text]

temperature radical isomerization reactions. Both the length and position of alkyl substitutions in aromatics affects is important, as evidenced by comparing the reactivity of ethylbenzene and various xylene isomers [89-91]. For the aforementioned reasons, Abdul Jameel et al. [46] recently introduced a BI term to quantify the arrangement of functional groups in a molecule. The location of important functional groups (e.g., alkyl substitutions) in the $\mathrm{Bl}$ is determined by a position index $(\mathrm{PI})$ term. The $\mathrm{BI}$ of a complex fuel mixture can be fully quantified from its ${ }^{1} \mathrm{H}$ NMR spectra, as shown in [46], which reports the BI for the 6 FACE gasolines studied in this work.

The $\mathrm{BI}$ for n-paraffins is set to be zero. For iso-paraffins, the $\mathrm{Bl}$ is defined as per Eq. (1).

$B I_{i-p}=\frac{\text { Number of } C \text { atoms connected to the longest chain }+P I \text { of each } C \text { connected to the longest chain }}{\text { Number of } C \text { atoms in the longest chain }}$

Where $\mathrm{PI}$ is the position index. In a molecule, when the methyl branch is at the outermost position of the chain, the DCN is higher compared to its isomer where the methyl branch moves to the interior. 2methylheptane has a higher DCN of 52.6 compared to 3-methylheptane which has a DCN of 45 . This is also true for other iso-paraffins. Eqs. (2) - (4) give the value of $\mathrm{PI}$ as defined by [46].

$P I=0$, if the $C$ atom is connected to the outermost position of the longest chain

$P I=0.5$, if the $C$ atom is connected 1 position away from the outermost position of the longest chain

$P I=0.5+$

0.5 , if the $C$ atom is connected 2 positions away from the outermost position of the longest chain and so on (4)

For example, consider the $\mathrm{BI}$ calculation for 3-methylpentane. There are $5 \mathrm{C}$ atoms in its longest chain to which $1 \mathrm{C}$ atom (3-methyl) is connected one position away from the outermost position. Thus, the $\mathrm{Pl}$ is 0.5 and the $\mathrm{BI}$ of 3-methylpentane is calculated as 0.3 . This definition of $\mathrm{BI}$ helps to explain the lower DCN of 3-methylpentane (30.7) compared to the DCN of 2-methylpentane (34.5), which has a BI of 0.2.

The $\mathrm{BI}$ of branched olefins is calculated similar to iso-paraffins. The $\mathrm{BI}$ of alkyl-naphthenes and alkyaromatic molecules has also been defined by re-drawing the ringed structures akin to iso-paraffins by reducing the rings to a single $\mathrm{C}$ atom. The $\mathrm{BI}$ of real fuels like gasoline and diesel can also be calculated. For more detailed information about the definition of $\mathrm{BI}$ and its calculation, please refer to [46]. Equations for calculating BI of alkyl-naphthenes, alkyl-aromatics, and real fuels are presented in the Supplementary Material. 
[Type text]

Table 1

${ }^{1} \mathrm{H}$ NMR assignments of the functional groups

\begin{tabular}{cll}
\hline $\begin{array}{c}\text { Chemical shift region } \\
(\mathrm{ppm})\end{array}$ & \multicolumn{1}{c}{$\mathrm{H}$ type } & Integral intensity \\
\hline $6.42-8.99$ & aromatics & $\mathrm{A}$ \\
$4.50-6.42$ & olefinic $\mathrm{CH}$ and $\mathrm{CH}_{2}$ groups & $\mathrm{B}$ \\
$2.88-3.40$ & $\alpha-\mathrm{CH}$ & $\mathrm{C}$ \\
$2.64-2.88$ & $\alpha-\mathrm{CH}_{2}$ & $\mathrm{D}$ \\
$2.04-2.64$ & $\alpha-\mathrm{CH}_{3}$ & $\mathrm{E}$ \\
$1.57-1.96$ & naphthenic $\mathrm{CH}$ and $\mathrm{CH} \mathrm{H}_{2}$ groups & $\mathrm{F}$ \\
$1.39-1.57$ & paraffinic $\mathrm{CH}$ groups & $\mathrm{G}$ \\
$0.94-1.39$ & paraffinic $\mathrm{CH}_{2}$ groups & $\mathrm{H}$ \\
$0.25-0.94$ & paraffinic $\mathrm{CH}_{3}$ groups & $\mathrm{I}$ \\
& Total $(\mathrm{A}+\mathrm{B}+\mathrm{C}+\mathrm{D}+\mathrm{E}+\mathrm{F}+\mathrm{G}+\mathrm{H}+\mathrm{l})$ & $\mathrm{T}$ \\
\hline
\end{tabular}


[Type text]

\section{Table 2}

Formulas used to calculate the weight $\%$ of the functional groups

\begin{tabular}{|c|c|c|c|}
\hline $\begin{array}{l}\text { Functional } \\
\text { groups }\end{array}$ & $\begin{array}{l}\text { H type } \\
\text { (mol \%) }\end{array}$ & $\begin{array}{l}\text { Weight } \\
\text { (g) }\end{array}$ & $\begin{array}{c}\text { Weight } \\
(\%)\end{array}$ \\
\hline Paraffinic $\mathrm{CH}_{3}$ & $M_{P_{C_{3}}}=\frac{(I+E)}{T} * 100$ & $G_{P_{C_{3}}}=\frac{M_{P_{C H_{3}}} * 15}{3}$ & $W_{P_{C_{3}}}=\frac{G_{P_{C H_{3}}} * 100}{G_{P_{C_{3}}}+G_{P_{C_{2}}}+G_{P_{C H}}+G_{O_{C H . C H_{2}}}+G_{N_{C H . C H}}+G_{A_{C . C H}}}$ \\
\hline Paraffinic $\mathrm{CH}_{2}$ & $M_{P_{C_{2}}}=\frac{(H+D)}{T}$ & $G_{P_{\mathrm{CH}_{2}}}=\frac{M_{\mathrm{P}_{\mathrm{CH}_{2}}} * 14}{2}$ & $W_{P_{C_{2}}}=\frac{G_{P_{C H_{2}}} * 100}{G_{P_{C_{3}}}+G_{P_{C_{2}}}+G_{P_{C H}}+G_{O_{C H . C H_{2}}}+G_{N_{C H . C H}}+G_{A_{C . C H}}}$ \\
\hline Paraffinic $\mathrm{CH}$ & $M_{P_{C H}}=\frac{(G+C)}{T} * 100$ & $G_{P_{C H}}=\frac{M_{P_{C H}} * 13}{1}$ & $W_{P_{C H}}=\frac{G_{P_{C H}} * 100}{G_{P_{C_{3}}}+G_{P_{C_{2}}}+G_{P_{C H}}+G_{O_{C H . C H_{2}}}+G_{N_{C H . C H}}+G_{A_{C . C H}}}$ \\
\hline Olefinic $\mathrm{CH}-\mathrm{CH}_{2}$ & $M_{\mathrm{O}_{\mathrm{CH} . \mathrm{CH}}}=\frac{B}{T} * 100$ & $G_{\mathrm{CH} . \mathrm{CH}_{2}}=\frac{M_{\mathrm{O}_{\mathrm{CH} . \mathrm{CH}}} * 13.5}{1.5}$ & 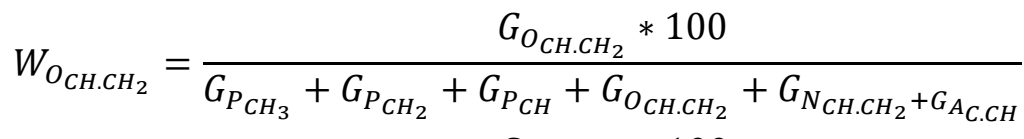 \\
\hline $\begin{array}{l}\text { Naphthenic } \mathrm{CH}- \\
\mathrm{CH}_{2}\end{array}$ & $M_{\mathrm{N}_{\mathrm{CH} . C H_{2}}}=\frac{F}{T} * 100$ & $G_{N_{\mathrm{CH} \mathrm{CH}}}=\frac{M_{\mathrm{N}_{\mathrm{CH} . \mathrm{CH}}} * 13.5}{1.5}$ & $W_{N_{C . C H_{2}}}=\frac{G_{N_{C H . C H}} * 100}{G_{P_{C_{3}}}+G_{P_{C_{2}}}+G_{P_{C H}}+G_{O_{C H . C H}}+G_{N_{C H . C H}}+G_{A_{C . C H}}}$ \\
\hline$\alpha-\mathrm{CH}$ & $M_{\alpha-\mathrm{CH}}=\frac{C}{T} * 100$ & & \\
\hline$\alpha-\mathrm{CH}_{2}$ & $M_{\alpha-\mathrm{CH}_{2}}=\frac{D}{T} * 100$ & & \\
\hline$\alpha-\mathrm{CH}_{3}$ & $M_{\alpha-\mathrm{CH}_{3}}=\frac{E}{T} * 100$ & & \\
\hline Aromatic $\mathrm{C}-\mathrm{CH}$ & $M_{A_{C . C H}}=\frac{A}{T} * 100$ & $\begin{array}{r}G_{A_{C . C H}}=\frac{M_{A_{C . C H}} * 13}{1}+\frac{M_{\alpha-\mathrm{CH}} * 13}{1} \\
+\frac{M_{\alpha-\mathrm{CH}_{2}} * 14}{2} \\
+\frac{M_{\alpha-\mathrm{CH}_{3}} * 15}{3}\end{array}$ & $W_{A_{C . C H}}=\frac{G_{A_{C . C H}} * 100}{G_{P_{C H_{3}}}+G_{P_{C H_{2}}}+G_{P_{C H}}+G_{O_{C H . C H_{2}}}+G_{N_{C . C H_{2}}+G_{A_{C . C H}}}}$ \\
\hline
\end{tabular}


[Type text]

\subsection{Surrogate fuel formulation}

After determining the functional groups and $\mathrm{BI}$ in the FACE gasoline fuels using ${ }^{1} \mathrm{H} N M R$, a systematic survey of several molecules was carried out to identify candidates that best match the target functional groups. The $\mathrm{BI}$ was not explicitly considered as a constraint during this screening, but the selected molecules enable close matching of $\mathrm{BI}$, as shown below. An attempt was made to use molecules with multiple chemical functionalities (like indane and tetralin as they contain aromatic and naphthenic rings in a single molecule), so that a minimal number of species could be used in the surrogate to match the functional groups. The surrogate molecules selected to represent the FACE gasolines are shown in Fig. 2 along with their BI values. The calculation of the $\mathrm{BI}$ for the individual molecules is presented in Fig. S1 in the supplementary material. The compositions of the surrogates are presented in Table 3. FACE A gasoline is represented by 2,4dimethylpentane and FACE I by 3-methylpentane. These fuels are primarily composed of $n$ paraffins and iso-paraffins and contain very low percentages of olefinic $\mathrm{CH}=\mathrm{CH}_{2}$, naphthenic $\mathrm{CH}$ $\mathrm{CH}_{2}$ and aromatic $\mathrm{C}-\mathrm{CH}$ groups, and therefore these functional groups were neglected when formulating the surrogates. FACE F and G gasolines contain all the four hydrocarbon classes with low percentage of olefinic $\mathrm{CH}=\mathrm{CH}_{2}$ groups ( $<2 \mathrm{wt} \%$ ). FACE F gasoline was represented with two molecules, specifically, 3-methylpentane and indane. FACE G gasoline has more naphthenic content than FACE F gasoline, and therefore was represented with 3-methylpentane and tetralin. The naphthenic content of tetralin is higher than that of indane, so the latter is better suited as a surrogate candidate for FACE G gasoline. FACE C gasoline (like FACE A) is also rich in paraffins but contains low percentage of aromatic and naphthenic groups ( $2 \mathrm{wt} \%)$, so was represented by 3-methylpentane and tetralin. Two surrogate compositions were formulated for FACE G gasoline (named $S_{1}$ and $S_{2}$ ), both of which closely resemble the fuel. This was done to obtain a quantitative understanding of the relationship between functional groups and various combustion properties, as discussed later. FACE I gasoline is rich in paraffins, similar to FACE A and $\mathrm{C}$, so was represented by 3-methylpentane. FACE J gasoline comprises more aromatic $\mathrm{C}-\mathrm{CH}$ groups compared to the other fuels and almost no naphthenic or olefinic groups. The surrogate for FACE J gasoline was formulated as a mixture of $n$-heptane and toluene. 
[Type text]

\section{Table 3}

Composition of the FACE gasoline surrogates

\begin{tabular}{|c|c|c|c|c|c|c|c|c|c|c|c|c|c|c|}
\hline \multirow[t]{2}{*}{ Species } & \multicolumn{2}{|c|}{$\begin{array}{c}\text { FACE A } \\
(\%)\end{array}$} & \multicolumn{2}{|c|}{$\begin{array}{c}\text { FACE C } \\
(\%)\end{array}$} & \multicolumn{2}{|c|}{$\begin{array}{c}\text { FACE F } \\
(\%)\end{array}$} & \multicolumn{2}{|c|}{$\begin{array}{c}\text { FACE G } \\
\text { Surro } 1(\%)\end{array}$} & \multicolumn{2}{|c|}{$\begin{array}{c}\text { FACE G } \\
\text { Surro } 2(\%)\end{array}$} & \multicolumn{2}{|c|}{$\begin{array}{c}\text { FACE I } \\
(\%)\end{array}$} & \multicolumn{2}{|c|}{$\begin{array}{c}\text { FACE J } \\
(\%)\end{array}$} \\
\hline & $\mathrm{mol}$ & wt & $\mathrm{mol}$ & wt & $\mathrm{mol}$ & wt & $\mathrm{mol}$ & wt & $\mathrm{mol}$ & wt & $\mathrm{mol}$ & wt & $\mathrm{mol}$ & wt \\
\hline $\begin{array}{c}\text { 2,4- } \\
\text { dimethylpentane }\end{array}$ & 100 & 100 & - & - & - & - & - & - & - & - & - & - & - & - \\
\hline 3-methylpentane & - & - & 96 & 94 & 79.6 & 74 & 67.9 & 58 & 69.7 & 60 & 100 & 100 & - & - \\
\hline indane & - & - & - & - & 20.4 & 26 & - & - & - & - & - & - & - & - \\
\hline tetralin & - & - & 4 & 6 & - & - & 32.1 & 42 & 30.3 & 40 & - & - & - & . \\
\hline n-heptane & - & - & - & - & - & - & - & - & - & - & - & - & 52.9 & 55 \\
\hline toluene & - & - & - & - & - & - & - & - & - & - & - & - & 47.1 & 45 \\
\hline
\end{tabular}

A comparison of the functional groups present in the FACE gasoline fuels and their respective MFG surrogates is shown in Fig. 3. The olefinic $\mathrm{CH}=\mathrm{CH}_{2}$ groups were neglected when formulating surrogates for all the FACE gasolines studied in the present work, due to their negligible percentages. Surrogate molecules were shortlisted by also considering their ability to emulate properties likes molecular weight and practical constraints of price and availability besides the primary goal of matching the functional group distribution. The novelty of these surrogates lies in the manner in which they were chosen and not the surrogates themselves. Other molecules can also be used as potential surrogate species as long as they match the functional groups and mirror the molecular size of the intended fuel. The development of chemical kinetic models for the surrogates is outside the scope of the present work, and therefore was not pursued.

The $\mathrm{BI}$ term has been shown to directly influence a fuel's cetane number [[46], and therefore the $\mathrm{BI}$ captures the effects of molecular structure on low temperature reactivity. The $\mathrm{BI}$ term was included as a target in this work when formulating surrogates for the various gasoline fuels. Table 4 compares the BI of FACE gasoline fuels with the MFG surrogates proposed herein. The $\mathrm{Bl}$ of surrogates with 2 components is the summation of the product of mole fraction of the constituent species with their respective Bl's. The comparison shows that the BI matches well for all 
[Type text]

fuels except FACE J. Nevertheless, the combustion properties (ignition delay and sooting index) for FACE J MFG surrogate matched well with the real fuel (as shown in the following Sections).

\section{Table 4}

Comparison of Branching Index (BI) of FACE gasoline fuels and their MFG surrogates

\begin{tabular}{crr}
\hline \multirow{2}{*}{ Gasoline } & \multicolumn{2}{c}{$B$ (no units) } \\
\cline { 2 - 3 } FACE A & 0.42 & 0.4 \\
FACE C & 0.31 & 0.34 \\
FACE F & 0.68 & 0.55 \\
FACE G & 0.76 & $0.68\left(\mathrm{~S}_{1}\right)$ \\
& & $0.66\left(\mathrm{~S}_{2}\right)$ \\
& & 0.3 \\
FACE I & 0.38 & 0.47 \\
\hline FACE J & 0.68 & \\
\hline $\begin{array}{l}S_{1} \text { and } S_{2} \text { refer to surrogates 1 \& 2, } \\
\text { respectively. }\end{array}$ &
\end{tabular}

A number of multicomponent surrogates have been reported in the literature for the various FACE gasolines studied in the present work. Tables 5, 6, 7, 8, 9 and 10 compare the functional groups in the MFG surrogates and other multi-component surrogates for FACE gasolines A, C, F, G, I and J, respectively. It can be seen that most of the multi-component surrogates match the functional group distribution of the fuel to various extents, but do so using a greater number of species. The MFG surrogates contain fewer components, but succeed in reproducing the combustion characteristics of the target gasoline (see R\&D section below). The MFG surrogate for FACE A gasoline matches the target functional groups more closely than the 5 component surrogate by Sarathy et al. [36], Ahfaz et al. [3] and Elwardany et al. [11]. The PRF surrogates reported by Bhavani Shankar et al. [30] for FACE C gasoline matches the functional groups of the target fuels as closely as the 6 component surrogates by Sarathy et al. [36] and Ahfaz et al. [3] and performs well in replicating the gas phase kinetics and the Low Temperature Heat Release (LTHR). The 6 component surrogate for FACE F gasoline developed by Sarathy et al. 
[Type text]

[69] matches the target functional groups more closely than the present 2-component MFG surrogate, but the latter is still successful in replicating the NTC behavior of the target gasoline (see section 4.3). Therefore, surrogates containing fewer species while matching the target functional groups can be equally effective as multicomponent surrogates with greater number more species.

Table 5

FACE A gasoline: comparison of MFG surrogate with multicomponent surrogates reported in literature

\begin{tabular}{|c|c|c|c|c|c|c|c|}
\hline $\begin{array}{l}\text { Functional } \\
\text { groups }\end{array}$ & unit & $\begin{array}{l}\text { FACE } \\
\text { gasoline }\end{array}$ & $\begin{array}{l}\text { MFG } \\
\text { surrogate }\end{array}$ & $\begin{array}{l}\text { Bhavanishankar } \\
\text { et al [30] }\end{array}$ & $\begin{array}{l}\text { Sarathy et al } \\
{[36]}\end{array}$ & Ahfaz et al [3] & $\begin{array}{l}\text { Elwardany et al } \\
\text { [11] }\end{array}$ \\
\hline & & & $\begin{array}{l}\text { 2,4-dimethyl } \\
\text { pentane }\end{array}$ & $\begin{array}{l}n \text {-heptane } \\
\text { iso-octane }\end{array}$ & $\begin{array}{l}\text { n-butane } \\
\text { 2-methyl butane } \\
\text { 2-methyl hexane } \\
\text { n-heptane } \\
\text { iso-octane* }\end{array}$ & $\begin{array}{l}\text { n-butane } \\
\text { 2-methyl butane } \\
\text { 2-methyl hexane } \\
\text { n-heptane } \\
\text { iso-octane* }\end{array}$ & $\begin{array}{l}\text {-butane } \\
\text { 3-methyl hexane } \\
n \text {-heptane } \\
\text { iso-octane } \\
1 \text { M-2P-cychexane }\end{array}$ \\
\hline $\begin{array}{l}\text { paraffinic } \\
\mathrm{CH}_{3}\end{array}$ & wt \% & 57.19 & 60 & 56.41 & 57.17 & 56.32 & 51.58 \\
\hline $\begin{array}{l}\text { paraffinic } \\
\mathrm{CH}_{2}\end{array}$ & wt \% & 16.99 & 14 & 21.46 & 21.71 & 23.15 & 26.72 \\
\hline $\begin{array}{c}\text { paraffinic } \\
\mathrm{CH}\end{array}$ & wt \% & 25.11 & 26 & 9.59 & 11.14 & 10.60 & 10.64 \\
\hline $\begin{array}{l}\text { Olefinic } \\
\mathrm{CH}=\mathrm{CH}_{2}\end{array}$ & wt \% & 0 & 0 & 0 & 0 & 0 & 0 \\
\hline $\begin{array}{l}\text { naphthenic } \\
\mathrm{CH}-\mathrm{CH}_{2}\end{array}$ & wt \% & 0.32 & 0 & 0 & 0 & 0 & 0.99 \\
\hline $\begin{array}{l}\text { aromatic } \\
\mathrm{C}-\mathrm{CH}\end{array}$ & wt \% & 0.41 & 0 & 0 & 0 & 0 & 0 \\
\hline
\end{tabular}

Table 6

FACE C gasoline: comparison of MFG surrogate with multicomponent surrogates reported in literature

\begin{tabular}{|c|c|c|c|c|c|c|c|}
\hline $\begin{array}{l}\text { Functional } \\
\text { groups }\end{array}$ & unit & $\begin{array}{l}\text { FACE } \\
\text { gasoline }\end{array}$ & MFG surrogate & $\begin{array}{l}\text { Bhavanishankar } \\
\text { et al [30] }\end{array}$ & $\begin{array}{l}\text { Mannaa et al } \\
\text { [92] }\end{array}$ & $\begin{array}{l}\text { Sarathy et al } \\
\text { [36] }\end{array}$ & $\begin{array}{l}\text { Ahfaz et al } \\
\text { [3] }\end{array}$ \\
\hline & & & $\begin{array}{l}\text { 3-methyl pentane } \\
\text { tetralin }\end{array}$ & $\begin{array}{l}n \text {-heptane } \\
\text { iso-octane* }\end{array}$ & $\begin{array}{l}n \text {-heptane } \\
\text { iso-octane* } \\
\text { toluene }\end{array}$ & $\begin{array}{l}n \text {-butane } \\
\text { 2-methyl } \\
\text { butane } \\
\text { 2-methyl } \\
\text { hexane } \\
n \text {-heptane } \\
\text { iso-octane* } \\
\text { toluene }\end{array}$ & $\begin{array}{l}n \text {-butane } \\
2 \text {-methyl } \\
\text { butane } \\
\text { 2-methyl } \\
\text { hexane } \\
n \text {-heptane } \\
\text { iso-octane* } \\
\text { toluene }\end{array}$ \\
\hline $\begin{array}{l}\text { paraffinic } \\
\mathrm{CH}_{3}\end{array}$ & wt \% & 53.82 & 49.19 & 56.41 & 54.51 & 54.87 & 53.57 \\
\hline $\begin{array}{l}\text { paraffinic } \\
\mathrm{CH}_{2}\end{array}$ & wt $\%$ & 33.12 & 30.6 & 21.46 & 20.98 & 23.95 & 24.69 \\
\hline $\begin{array}{c}\text { paraffinic } \\
\mathrm{CH}\end{array}$ & wt $\%$ & 9.44 & 14.21 & 9.59 & 9.11 & 9.18 & 8.56 \\
\hline $\begin{array}{l}\text { Olefinic } \\
\mathrm{CH}=\mathrm{CH}_{2}\end{array}$ & wt $\%$ & 0 & 0 & 0 & 0 & 0 & 0 \\
\hline
\end{tabular}


[Type text]

\begin{tabular}{lccccccc}
$\begin{array}{l}\text { naphthenic } \\
\mathrm{CH}-\mathrm{CH}_{2}\end{array}$ & wt \% & 2.8 & 2.54 & 0 & 0 & 0 & 0 \\
$\begin{array}{l}\text { aromatic } \\
\text { C-CH }\end{array}$ & wt \% & 0.82 & 3.45 & 0 & 3.48 & 2.36 & 3.76 \\
\hline
\end{tabular}

* refers to 2,2,4-trimethyl pentane;

Table 7

FACE F gasoline: comparison of MFG surrogate with multicomponent surrogates reported in literature

\begin{tabular}{|c|c|c|c|c|c|c|c|}
\hline $\begin{array}{l}\text { Functional } \\
\text { groups }\end{array}$ & unit & $\begin{array}{l}\text { FACE } \\
\text { gasoline }\end{array}$ & MFG surrogate & $\begin{array}{l}\text { Mannaa et al } \\
\text { [92] }\end{array}$ & $\begin{array}{l}\text { Sarathy et al } \\
\text { [69] }\end{array}$ & $\begin{array}{l}\text { Sarathy et al } \\
\text { [69] }\end{array}$ & $\begin{array}{l}\text { Sarathy et al } \\
\text { [69] }\end{array}$ \\
\hline & & & $\begin{array}{l}\text { 3-methyl pentane } \\
\text { indane }\end{array}$ & $\begin{array}{l}n \text {-heptane } \\
\text { iso-octane* } \\
\text { toluene }\end{array}$ & $\begin{array}{l}\text { n-heptane } \\
\text { iso-octane* } \\
\text { toluene }\end{array}$ & $\begin{array}{l}n \text {-butane } \\
\text { n-heptane } \\
\text { iso-octane* } \\
\text { 1-hexene } \\
\text { cyclo-pentane } \\
\text { toluene }\end{array}$ & $\begin{array}{l}n \text {-butane } \\
\text { 2-methyl } \\
\text { butane } \\
\text { 2-methyl } \\
\text { hexane iso- } \\
\text { octane } \\
\text { 1-hexene } \\
\text { cyclo-pentane } \\
1,2,4-T M B^{\#}\end{array}$ \\
\hline $\begin{array}{l}\text { paraffinic } \\
\mathrm{CH}_{3}\end{array}$ & wt \% & 48.58 & 38.72 & 57.71 & 42.11 & 43.09 & 47.11 \\
\hline $\begin{array}{l}\text { paraffinic } \\
\mathrm{CH}_{2}\end{array}$ & wt \% & 21.14 & 24.09 & 15.15 & 14.13 & 18.20 & 16.55 \\
\hline $\begin{array}{c}\text { paraffinic } \\
\mathrm{CH}\end{array}$ & wt $\%$ & 6.01 & 11.18 & 10.26 & 6.15 & 6.88 & 8.26 \\
\hline $\begin{array}{l}\text { Olefinic } \\
\mathrm{CH}=\mathrm{CH}_{2}\end{array}$ & wt \% & 1.95 & 0 & 0 & 0 & 3.77 & 2.36 \\
\hline $\begin{array}{l}\text { naphthenic } \\
\mathrm{CH}-\mathrm{CH}_{2}\end{array}$ & wt \% & 9.82 & 9.36 & 0 & 0 & 9.80 & 11.51 \\
\hline $\begin{array}{l}\text { aromatic } \\
\mathrm{C}-\mathrm{CH}\end{array}$ & wt \% & 12.49 & 16.64 & 3.43 & 29.55 & 9.23 & 6.55 \\
\hline
\end{tabular}

* refers to 2,2,4-trimethyl pentane; \# refers to 1,2,4-trimethyl benzene;

Table 8

FACE G gasoline: comparison of MFG surrogate with multicomponent surrogates reported in literature

\begin{tabular}{|c|c|c|c|c|c|c|c|}
\hline $\begin{array}{l}\text { Functional } \\
\text { groups }\end{array}$ & unit & $\begin{array}{l}\text { FACE } \\
\text { gasoline }\end{array}$ & $\begin{array}{l}\text { MFG surrogate } \\
\left(\mathrm{S}_{1}\right)\end{array}$ & $\begin{array}{l}\text { MFG surrogate } \\
\left(S_{2}\right)\end{array}$ & $\begin{array}{l}\text { Sarathy } \\
\text { et al [69] }\end{array}$ & $\begin{array}{l}\text { Sarathy } \\
\text { et al [69] }\end{array}$ & $\begin{array}{l}\text { Sarathy } \\
\text { et al [69] }\end{array}$ \\
\hline & & & $\begin{array}{l}\text { 3-methyl pentane } \\
\text { tetralin }\end{array}$ & $\begin{array}{l}\text { 3-methyl pentane } \\
\text { tetralin }\end{array}$ & $\begin{array}{l}n \text {-heptane } \\
\text { iso-octane* } \\
\text { toluene }\end{array}$ & $\begin{array}{l}\text { n-heptane } \\
\text { iso-octane* } \\
1 \text {-hexene } \\
\text { cyclo- } \\
\text { pentane } \\
1,2,4-T M B^{\#}\end{array}$ & $\begin{array}{l}\text { n-butane } \\
\text { 2-methyl butane } \\
\text { 2-methyl hexane } \\
\text { iso-octane* } \\
\text { 1-hexene } \\
\text { cyclo-pentane } \\
\text { toluene } \\
1,2,4-T M B^{\#}\end{array}$ \\
\hline $\begin{array}{l}\text { paraffinic } \\
\mathrm{CH}_{3}\end{array}$ & wt \% & 37.11 & 31.56 & 30.34 & 22.04 & 41.84 & 38.09 \\
\hline $\begin{array}{l}\text { paraffinic } \\
\mathrm{CH}_{2}\end{array}$ & wt \% & 18.01 & 19.64 & 18.88 & 12.28 & 13.89 & 14.33 \\
\hline $\begin{array}{c}\text { paraffinic } \\
\mathrm{CH}\end{array}$ & wt \% & 7.01 & 9.12 & 8.76 & 0.89 & 4.66 & 5.25 \\
\hline $\begin{array}{l}\text { Olefinic } \\
\mathrm{CH}=\mathrm{CH}_{2}\end{array}$ & wt \% & 1.65 & 0 & 0 & 0 & 2.29 & 2.32 \\
\hline
\end{tabular}


[Type text]

\begin{tabular}{|c|c|c|c|c|c|c|c|}
\hline $\begin{array}{l}\text { naphthenic } \\
\mathrm{CH}-\mathrm{CH}_{2}\end{array}$ & wt \% & 12.70 & 16.86 & 17.85 & 0 & 9.25 & 11.37 \\
\hline $\begin{array}{l}\text { aromatic } \\
\mathrm{C}-\mathrm{CH}\end{array}$ & wt \% & 23.51 & 22.84 & 24.15 & 63.61 & 21.95 & 25.47 \\
\hline
\end{tabular}

* refers to 2,2,4-trimethyl pentane; \# refers to 1,2,4-trimethyl benzene;

Table 9

FACE I gasoline: comparison of MFG surrogate with multicomponent surrogates reported in literature

\begin{tabular}{|c|c|c|c|c|c|c|}
\hline $\begin{array}{l}\text { Functional } \\
\text { groups }\end{array}$ & unit & $\begin{array}{l}\text { FACE } \\
\text { gasoline }\end{array}$ & MFG surrogate & $\begin{array}{l}\text { Bhavanishankar } \\
\text { et al [30] }\end{array}$ & Javed et al [93] & Elwardany et al [94] \\
\hline & & & 3-methyl pentane & $\begin{array}{l}n \text {-heptane } \\
\text { iso-octane* }\end{array}$ & $\begin{array}{l}\text { 2-methyl butane } \\
\text { 2-methyl hexane } \\
\text { n-heptane } \\
\text { iso-octane* } \\
\text { 1-hexene } \\
\text { cyclo-pentane } \\
1,2,4-T M B^{\#}\end{array}$ & $\begin{array}{l}\text { 2-methyl butane } \\
\text { 2-methyl hexane } \\
\text { n-heptane } \\
\text { iso-octane* } \\
\text { 2,3,4-trimethyl pentane } \\
\text { 1-hexene } \\
\text { methyl-cyclohexane } \\
\text { toluene }\end{array}$ \\
\hline $\begin{array}{l}\text { paraffinic } \\
\mathrm{CH}_{3}\end{array}$ & wt \% & 58.56 & 52.4 & 51.98 & 47.33 & 45.40 \\
\hline $\begin{array}{l}\text { paraffinic } \\
\mathrm{CH}_{2}\end{array}$ & wt \% & 30.55 & 32.5 & 29.59 & 28.64 & 29.29 \\
\hline $\begin{array}{c}\text { paraffinic } \\
\mathrm{CH}\end{array}$ & wt \% & 7.38 & 15.1 & 7.98 & 9.65 & 11.30 \\
\hline $\begin{array}{l}\text { Olefinic } \\
\mathrm{CH}=\mathrm{CH}_{2}\end{array}$ & wt \% & 1.42 & 0 & 0 & 1.62 & 1.89 \\
\hline $\begin{array}{l}\text { naphthenic } \\
\mathrm{CH}-\mathrm{CH}_{2}\end{array}$ & wt \% & 1.61 & 0 & 0 & 4.21 & 3.51 \\
\hline $\begin{array}{l}\text { aromatic } \\
\mathrm{C}-\mathrm{CH}\end{array}$ & wt \% & 0.48 & 0 & 0 & 3.01 & 3.90 \\
\hline
\end{tabular}

Table 10

FACE J gasoline: comparison of MFG surrogate with multicomponent surrogates reported in literature

\begin{tabular}{|c|c|c|c|c|c|c|}
\hline $\begin{array}{l}\text { Functional } \\
\text { groups }\end{array}$ & unit & $\begin{array}{l}\text { FACE } \\
\text { gasoline }\end{array}$ & MFG surrogate & $\begin{array}{l}\text { Bhavanishankar } \\
\text { et al [30] }\end{array}$ & $\begin{array}{l}\text { Mannaa et al } \\
\text { [92] }\end{array}$ & Javed et al [93] \\
\hline & & & $\begin{array}{l}n \text {-heptane } \\
\text { toluene }\end{array}$ & $\begin{array}{l}\text { n-heptane } \\
\text { iso-octane* }\end{array}$ & $\begin{array}{l}n \text {-heptane } \\
\text { iso-octane* } \\
\text { toluene }\end{array}$ & $\begin{array}{l}n \text {-butane } \\
\text { 2-methyl hexane } \\
n \text {-heptane } \\
\text { iso-octane* } \\
1,2,4-\text { TMB }^{\#}\end{array}$ \\
\hline $\begin{array}{l}\text { paraffinic } \\
\mathrm{CH}_{3}\end{array}$ & wt \% & 25.38 & 23.85 & 51.98 & 31.38 & 41.39 \\
\hline $\begin{array}{l}\text { paraffinic } \\
\mathrm{CH}_{2}\end{array}$ & wt $\%$ & 34.05 & 38.50 & 29.59 & 32.17 & 30.43 \\
\hline $\begin{array}{c}\text { paraffinic } \\
\mathrm{CH}\end{array}$ & wt \% & 7.25 & 0 & 7.98 & 2.34 & 4.62 \\
\hline $\begin{array}{l}\text { Olefinic } \\
\mathrm{CH}=\mathrm{CH}_{2}\end{array}$ & wt \% & 0 & 0 & 0 & 0 & 0 \\
\hline $\begin{array}{l}\text { naphthenic } \\
\mathrm{CH}-\mathrm{CH}_{2}\end{array}$ & wt \% & 0.81 & 0 & 0 & 0 & 0 \\
\hline $\begin{array}{l}\text { aromatic } \\
\mathrm{C}-\mathrm{CH}\end{array}$ & wt \% & 32.51 & 37.65 & 0 & 31.01 & 21.78 \\
\hline
\end{tabular}


* refers to 2,2,4-trimethyl pentane; \# refers to 1,2,4-trimethyl benzene;

\subsection{Ignition quality tester}

Numerous studies have used IQT to validate surrogates formulated for diesel fuels [35], jet fuels [18,23], gasoline $[4,6,7]$, and lubricant oils [95] as it enables quantification of the overall chemical reactivity of the fuel [18]. In addition the ease of operability, repeatability and small fuel requirement have made the IQT a standard device to characterize fuel reactivity. As liquid fuel is injected into the IQT combustion chamber, the IDT is a combination of physical processes (e.g., spray breakup, evaporation, mixing) followed by gas-phase chemical reactions leading to ignition [96]. The Total Ignition Delay (TID) is comprised of both the physical and chemical kinetic contributions; the relative importance of each depends on the fuel. Gasoline fuels are more volatile and less reactive than diesel fuels, and thus the TID of the former is primarily governed by gas-phase chemical reactions and not by physical processes. This has been experimentally demonstrated in Mendelson et al. [97], which separated the physical and chemical IDTs by analyzing the IQT pressure signal. For low DCN fuels (i.e., high octane gasolines), it was observed that chemical IDT dominated the total IDT, while the physical IDT was less important. The IQT determined ignition delay for FACE gasolines are more indicative of differences in the rate of gasphase chemical reactions rather than of physical processes.

FACE gasolines and their surrogates were tested in the KAUST research ignition quality tester (KR-IQT) obtained from Advanced Engine Technology Ltd. The IQT is a constant volume combustion chamber equipped with an S-type inward opening pintle nozzle [98] that injects liquid fuel into zero-air (air containing total hydrocarbons $<0.1 \mathrm{ppm}$ ) pressurized and preheated to standard pressure and temperature following ASTM standard D6890 [99]. The standard pressure $\left(P_{0}\right)$ prescribed in ASTM D6890 is 21 bar, however the standard temperature is not an exactly prescribed constant, rather it is adjusted by a calibration procedure, which involves the adjustment of charge temperature ( $T_{0}$, circa. $\left.821 \mathrm{~K}\right)$ such that the average of ignition delay time of three tests with $\mathrm{n}$-heptane is $3.78 \pm 0.01 \mathrm{~ms}$. Each test in the KR-IQT comprises of 15 preinjections followed by 32 main injection events, the pre-injection events are carried out to provide a steady stable combustion environment for the following main injection events. The 
ignition delay time reported in the present study is the average of the 32 main injections. For each injection, the ignition delay time is defined as the time difference between the start of injection (Solnj) and start of ignition (Solgn). The time at which the injector needle lift attains the maximum is defined as Solnj. For fuels that exhibit LTHR, standard IQT definitions for Solgn based on pressure rise $(\Delta \mathrm{P})$ are not suitable, as the pressure rise due to LTHR is falsely picked up as the main ignition event necessitating the application of a gradient method to define Solgn as described in [100]. The gradient method defines the Solgn as the intersecting point of the gradients at two points, one at the pressure recovery point and the other the maximum gradient during ignition pressure rise. The pressure recovery point is the point before ignition where the pressure in the chamber regains to the initial chamber pressure $\left(P_{0}\right)$ after evaporative cooling. Due to evaporative cooling of the liquid droplets, the pressure in the chamber drops and regains to initial chamber pressure as chemical reactions progresses. Additional details on the gradient method are available in $[100,101]$. The surrogate methodology tested here assumes that the ignition characteristics of FACE gasolines are primarily kinetically controlled, as indicated in previous works $[18,23,47]$. IQT measurements were only performed at the standard DCN conditions; to assess the performance of surrogate fuels at a wide range of temperatures the RCM was used, as discussed next.

\subsection{Rapid Compression Machine (RCM)}

Numerous studies have utilized RCM measurements for surrogate validation $[8,21,23,36,69]$. Ignition delay measurements of the FACE gasoline surrogates were carried out at 20 bar and at an equivalence ratio of 1 in the KAUST RCM, which has a dual opposed piston arrangement, similar to the National University of Ireland (NUI) Galway RCM [55]. The dual piston design possesses several advantages over the single piston arrangement, such as improved mechanical balance and lower compression times. In the KAUST RCM, the combustion chamber diameter is $50.8 \mathrm{~mm}$ and the total piston stroke length is $238 \mathrm{~mm}$. For the experiments reported here, a volumetric compression ratio of 13 was used. It takes about 16 ms to compress the mixture and most of the pressure rise occurs in the last 2-3 ms of the compression stroke. Pistons are driven pneumatically and locked at the end of compression by a hydraulic locking system. 
Insulated heating jackets are used to pre-heat the combustion chamber and piston sleeves. Pressure time-history profiles are obtained by a Kistler 6045A pressure transducer which is installed in the combustion chamber wall. Piston heads are designed with crevice volumes in order to suppress vortex formation and achieve near-homogeneous conditions [55].

Ignition delay time is defined as the duration from the peak pressure at the end of compression to the maximum pressure increase caused by the ignition process. The compressed gas temperature $\left(T_{c}\right)$ is calculated by using adiabatic compression/expansion Eq. (5).

$\ln \left(\frac{P_{c}}{P_{i}}\right)=\int_{T_{i}}^{T_{C}} \frac{\gamma}{\gamma-1} \frac{d T}{T}$

where $T_{i}$ and $P_{i}$ are the initial temperature and pressure of the mixture, whereas $T_{c}$ and $P_{c}$ are the compressed gas temperature and pressure, and $\gamma$ is the ratio of specific heats. The RCM experiments for FACE gasolines were carried out over a temperature range of $620-756 \mathrm{~K}$. Carbon dioxide dilution ( $75 \% \mathrm{~N}_{2} / 25 \% \mathrm{CO}_{2}$ ) was used to reach compressed temperatures of $620-670 \mathrm{~K}$, whereas $100 \% \mathrm{~N}_{2}$ was used as diluent gas for higher temperatures (> $670 \mathrm{~K}$ ). The uncertainty in RCM ignition delay time measurements is $\pm 15 \%$. The RCM measurements for FACE A, C, F and G gasolines were performed at the facility in UCONN, and the details can be found here $[36,69]$.

\subsection{Smoke Point Measurements}

The smoke point (SP) corresponds to the maximum height in $\mathrm{mm}$ of a smoke-free laminar non-premixed flame determined with an ASTM D1322 standard [102] smoke point lamp. The measurements were performed according to the procedure described by the ASTM D1322. ASTM D1322 defines six mixtures of toluene and 2,2,4-trimethylpentane (iso-octane) for calibration of the smoke point apparatus. For each fuel sample, the flame height at the SP was measured and recorded five times to the nearest millimetre, and subsequently averaged. Across all sets of measurements, the average standard deviation of the smoke point was $0.48 \mathrm{~mm}$, ranging from 0.45 to $0.55 \mathrm{~mm}$. This contributes to a total estimated uncertainty of $\pm 1.0 \mathrm{~mm}$. The impact on this uncertainty will be discussed in section 3.6.2. The measured smoke point data were analysed by using the Threshold Sooting Index (TSI) concept as introduced by Calcote and Manos [103]. 
The TSI is a function of the fuel smoke point and the fuel molecular weight (MW) as defined by Eq. (6):

$T S I=a\left(\frac{M W}{S P}\right)+b$

Here, $a$ and $b$ are apparatus-specific constants to set the TSI on a uniform scale with $a$ in $\left(\mathrm{mm}^{*}(\mathrm{~g} / \mathrm{mol})^{-1}\right)$ and $b$ unitless. The constants $a$ and $b$ were deduce from Eqs. (7) and (8) as defined in the literature [104,105] with 1-methylnaphtalene and methylcyclohexane have TSIs of 100 and 5 respectively:

$$
\begin{aligned}
& a=\frac{95}{\frac{M W}{S P}_{1-M N}+\frac{M W}{S P}_{M C H}} \\
& b=\frac{100 * \frac{M W}{S P}{ }_{M C H}+5 * \frac{M W}{S P}_{1-M N}}{\frac{M W}{S P}_{1-M N}+\frac{M W}{S P}_{M C H}}
\end{aligned}
$$

As described by Eq. (6), determination of TSI of requires knowledge of the fuel molecular weight. In the case of practical fuels, such as FACE gasoline fuels, the molecular weight is difficult to precisely quantify. Cannella et al. [40] reported some physical and chemical properties of the FACE gasolines in Coordinating Research Council (CRC), but no information on the molecular weight was provided. Here, the average molecular weight of the FACE gasolines was calculated from the detailed compositional data contained in the detailed hydrocarbon analysis (DHA), and this data was used for determination of the TSI. The average molecular weights for FACE A, C, F and I are estimated to be accurate to $+/-5 \mathrm{~g} / \mathrm{mol}$ and $+/-20 \mathrm{~g} / \mathrm{mol}$ for FACE G and J presented details in Table 16.

\subsection{1 "Virtual" Smoke Point Measurements}

The smoke point of FACE gasolines ( $\mathrm{A}, \mathrm{C}$ and $\mathrm{I})$ and their respective MFG surrogates were out of range of the ASTM D1322 standard $(>50 \mathrm{~mm})$ and cannot be determined with this method. For these fuels, a "Virtual" Smoke Point (VSP) compatible with the ASTM D1322 standard was extracted using the extrapolation method described by Haas et al. [106]. This method exploits the lower smoke points acquired by the mixing of a "poorly" sooting fuel, with a "well" sooting fuel. Binary mixtures of such compositions at appropriate fractions were designed to obtain 
measureable smoke point by the ASTM D1322 standard. When these measured smoke points are analysed as a function of blending mole fraction a variable and non-linear relationship results. Knowledge of this functional relationship is therefore required in order to extrapolate the blend mole fraction to the value corresponding to the full absence of the "well" sooting fuel. To resolve this difficulty Haas et al. [106] cleverly suggest exploiting the empirically demonstrated molar linearity of the TSI to the blend fraction of binary mixtures defined by Eq. (9):

$T S I_{\text {mix }}=\sum_{i} x_{i} T S I_{i}$

Where, $X_{i}$ is the mole fraction of component $i$ in range of $0 \leq X_{i} \leq 1$.

According to the molar linearity of the TSI and for a fuel mixture $i-j$, the $T S I_{i-j}$ can be expressed by Eq. (10):

$T S I_{i-j}=m_{i-j} X_{j}+T S I_{i}$

Where, $X_{j}$ is the mole fraction of component $j$ in range of $0 \leq X_{j} \leq 1$ and $m_{i-j}$ is the slope of the linear relationship between the TSI and the mole fraction of the binary mixture of component $i$ and component $j$. From Eqs. (6) to (10), the VSP can be expressed by the linear expression shown by Eq. (11):

$\frac{M W_{i-j}}{S P_{i-j}}=\frac{m_{i-j}}{a} X_{j}+\frac{M W_{i}}{S P_{i}}$

Where $\frac{m_{i-j}}{a}$ is the slope of the relation above, $a$ is the apparatus-specific constant of the TSI definition, and $\mathrm{MW}_{i-j}$ the average molecular weight of the binary mixture. From Eq. (11), the VSP can be extrapolated by plotting $\frac{M W_{i-j}}{S P_{i-j}}$ against blend mole fractions. This procedure is essentially what Mensch et al. [105] previously utilised to determine the TSI of iso-cetane, another fuel component outside the range of ASTM D1322. Utilizing this "Virtual" smoke point technique, a series of measurements were performed by binary molar blending of FACE A, C, I and their respective MFG surrogate fuels, with toluene and $n$-butylbenzene as separate blend stocks. At least four different blending ratios for each compositions were performed to determine the extrapolated quantities with high confidence. 


\subsubsection{Uncertainties}

For the preparation of surrogates, the mass of the individual pure fuel components comprising the pertinent surrogate definitions was measured using an analytical balance of $0.001 \mathrm{~g}$ precision. The resulting uncertainty on the molar ratio to the fuel blend for a $50 \mathrm{~g}$ mass was approximately $0.01 \%$, which was considered negligible and not taken into further consideration. The uncertainty due to the determination of the smoke point was assumed to be $\pm 1.0 \mathrm{~mm}$, as explained above, for all measurements. The resulting standard uncertainty on the threshold sooting index and virtual smoke point was calculated as the root-mean-square sum of the respective contributors, therefore considering uncertainties in molecular weight, smoke point determination, blend fraction definition, and extrapolation to pure component blend fraction. The resulting uncertainties are presented in Table 6.

\section{RESULTS \& DISCUSSION}

\subsection{Physical and chemical properties}

When surrogates are chosen such that they match the functional groups in the target fuel, the physical and chemical properties are likely to be matched. The surrogate fuel components were chosen and formulated such that they mirror the general molecular size of the FACE gasolines, as indicated by average molecular weight. In doing so the physical properties of the surrogate are likely to match those of the target fuel. Thus, the functional groups and molecular weight possess enough molecular information of the fuel to explain both the physical and the chemical properties $[18,23,34]$. Select macroscopic physical properties, such as density and average molecular weight, and select macroscopic chemical properties, such as $\mathrm{H} / \mathrm{C}$ ratio and heat of combustion of the FACE gasoline fuels are compared with their respective MFG surrogates in Fig. 4. The average molecular weight of the FACE gasolines were calculated from the detailed compositional data contained in the DHA. The other properties of the FACE gasolines were taken from the CRC report [40]. The density and heat of combustion of the two component surrogates (for FACE C, F, G and J gasolines) were calculated from the data of the individual 
components using linear-by-mass additivity rules. Data for the individual components were taken from the NIST database [107].

Fig. 4 shows that the properties of the surrogates and the target fuels match well. The MFG surrogates for FACE A gasoline (2,4-dimethylpentane) has slightly lower density, as the target fuels possess small quantities $(\approx 0.5 \%)$ of aromatic $\mathrm{C}-\mathrm{CH}$ and naphthenic $\mathrm{CH}-\mathrm{CH}_{2}$ groups. Aromatic $\mathrm{C}-\mathrm{CH}$ and naphthenic $\mathrm{CH}-\mathrm{CH}_{2}$ groups are more dense compared to paraffinic groups, as seen from pure compound densities; benzene $(1.12 \mathrm{~g} / \mathrm{ml})$; cyclohexane $(0.93 \mathrm{~g} / \mathrm{ml})$ and $\mathrm{n}$-hexane $(0.76 \mathrm{~g} / \mathrm{ml})$. A similar case is seen for the case of FACE I surrogate (3-methylpentane). The surrogates for FACE F, G and J gasolines contain slightly more aromatic $\mathrm{C}-\mathrm{CH}$ and naphthenic $\mathrm{CH}$ $\mathrm{CH}_{2}$ groups than the target fuels, and hence are slightly denser. The surrogate for FACE C gasoline matches the target fuel's functional groups very well. The difference in density of all the FACE gasolines and their respective MFG surrogates is less than $5 \%$, except for FACE F where the difference is around $6.2 \%$. Molecular weight of the fuel correlates strongly with the gas phase diffusive properties [33] and a mismatch could result in a poorer emulation of combustion kinetic phenomena that are diffusive in nature, e.g. smoke point. A good match is seen between the average molecular weights of the FACE gasolines and their respective MFG surrogates, except for FACE $C$ and I where the difference is around 10 and $9.9 \%$ respectively.

The $\mathrm{H} / \mathrm{C}$ ratio of FACE G and J gasolines is lower compared to the other FACE gasolines due to the noted high aromatic content. The MFG surrogates replicate the H/C ratio of all the FACE gasolines, wherein the differences are less than $4 \%$, except for FACE F where the difference is $5.6 \%$. The nature of the chemical bonds in hydrocarbon molecules defines the heat of combustion, and therefore the latter can be directly evaluated from the knowledge of the functional groups present in the reactant and product molecules. Paraffinic groups have a higher heat of combustion compared to aromatic $\mathrm{C}-\mathrm{CH}$ and naphthenic $\mathrm{CH}-\mathrm{CH}_{2}$ groups, as seen from the pure compound values; $\mathrm{n}$-hexane $(4.14 \mathrm{MJ} / \mathrm{mol})$; cyclohexane (3.92 MJ/mol); and benzene (3.03 $\mathrm{MJ} / \mathrm{mol})$. This gives the heat of combustion of a single paraffinic group to be $(0.69 \mathrm{MJ} / \mathrm{mol} . \mathrm{C})$, followed by naphthenic group (0.65 MJ/mol.C) and aromatic group ( $0.50 \mathrm{MJ} / \mathrm{mol}$.C). As expected, the MFG surrogates for FACE A and I gasolines possess a higher (>5\%) heat of combustion than 
their respective target fuels, as the surrogates are purely paraffinic. A better match is observed in the FACE F, G and J gasolines and their respective MFG surrogates that contain approximately the same quantities of all functional groups.

A comparison of the target physical and chemical properties of the MFG surrogates with other multicomponent surrogates are reported in Tables 11, 12, 13, 14, 15 and 16 for FACE gasolines A, C, F, G, I and J respectively. It can be observed that surrogates that match the target functional groups closely emulate the physical and chemical properties of the fuel closely as well. This is evident from Quantitative Structure-Property Relationship (QSPR) studies [41,44-46] that show that the properties of a compound are dependent on molecular descriptors (or functional groups) and molecular weight.

Table 11

FACE A gasoline: comparison of MFG surrogate with multicomponent surrogates reported in literature

\begin{tabular}{|c|c|c|c|c|c|c|c|}
\hline $\begin{array}{l}\text { Functional } \\
\text { groups }\end{array}$ & unit & $\begin{array}{l}\text { FACE } \\
\text { gasoline }\end{array}$ & $\begin{array}{l}\text { MFG } \\
\text { surrogate }\end{array}$ & $\begin{array}{l}\text { Bhavanishankar } \\
\text { et al [30] }\end{array}$ & $\begin{array}{l}\text { Sarathy } \\
\text { et al [36] }\end{array}$ & Ahfaz et al [3] & $\begin{array}{l}\text { Elwardany et al } \\
\text { [11] }\end{array}$ \\
\hline & & & $\begin{array}{l}\text { 2,4-dimethyl } \\
\text { pentane }\end{array}$ & $\begin{array}{l}n \text {-heptane } \\
\text { iso-octane }\end{array}$ & $\begin{array}{l}n \text {-butane } \\
\text { 2-methyl butane } \\
\text { 2-methyl hexane } \\
\text { n-heptane } \\
\text { iso-octane* }^{*}\end{array}$ & $\begin{array}{l}\text { n-butane } \\
\text { 2-methyl butane } \\
\text { 2-methyl hexane } \\
\text { n-heptane } \\
\text { iso-octane* }\end{array}$ & $\begin{array}{l}\text { n-butane } \\
\text { 3-methyl hexane } \\
n \text {-heptane } \\
\text { iso-octane } \\
1 \text { M-2P-cychexane }\end{array}$ \\
\hline density & $\mathrm{g} / \mathrm{ml}$ & 0.68 & 0.67 & 0.69 & 0.67 & 0.67 & 0.69 \\
\hline average MW & $\mathrm{g} / \mathrm{mol}$ & 99.78 & 100 & 111.52 & 101.26 & 101.80 & 92.74 \\
\hline $\mathrm{H} / \mathrm{C}$ ratio & molar & 2.29 & 2.28 & 2.25 & 2.25 & 2.25 & 2.26 \\
\hline $\begin{array}{l}\text { Heat of } \\
\text { combustion }\end{array}$ & $\mathrm{MJ} / \mathrm{kg}$ & 44.77 & 48.08 & 47.91 & 48.07 & 48.06 & 47.90 \\
\hline
\end{tabular}

* refers to 2,2,4-trimethyl pentane; \# refers to 1-methyl-2-propyl cyclohexane

Table 12

FACE C gasoline: comparison of MFG surrogate with multicomponent surrogates reported in literature

\begin{tabular}{|c|c|c|c|c|c|c|c|}
\hline $\begin{array}{l}\text { Functional } \\
\text { groups }\end{array}$ & unit & $\begin{array}{l}\text { FACE } \\
\text { gasoline }\end{array}$ & MFG surrogate & $\begin{array}{l}\text { Bhavanishankar } \\
\text { et al [30] }\end{array}$ & $\begin{array}{l}\text { Mannaa } \\
\text { et al [92] }\end{array}$ & $\begin{array}{l}\text { Sarathy et al } \\
\text { [36] }\end{array}$ & $\begin{array}{l}\text { Ahfaz et al } \\
\text { [3] }\end{array}$ \\
\hline & & & $\begin{array}{l}\text { 3-methyl pentane } \\
\text { tetralin }\end{array}$ & $\begin{array}{l}n \text {-heptane } \\
\text { iso-octane* }\end{array}$ & $\begin{array}{l}n \text {-heptane } \\
\text { iso- } \\
\text { octane* } \\
\text { toluene }\end{array}$ & $\begin{array}{l}n \text {-butane } \\
2 \text {-methyl } \\
\text { butane } \\
\text { 2-methyl } \\
\text { hexane } \\
n \text {-heptane } \\
\text { iso-octane* } \\
\text { toluene }\end{array}$ & $\begin{array}{l}n \text {-butane } \\
2 \text {-methyl } \\
\text { butane } \\
\text { 2-methyl } \\
\text { hexane } \\
n \text {-heptane } \\
\text { iso-octane* } \\
\text { toluene }\end{array}$ \\
\hline density & $\mathrm{g} / \mathrm{ml}$ & 0.69 & 0.67 & 0.69 & 0.70 & 0.67 & 0.68 \\
\hline
\end{tabular}


[Type text]

\begin{tabular}{lccccccc} 
average MW & $\mathrm{g} / \mathrm{mol}$ & 97.71 & 101.28 & 111.5 & 110.46 & 98.22 & 98.13 \\
$\mathrm{H} / \mathrm{C}$ ratio & molar & 2.21 & 2.28 & 2.25 & 2.20 & 2.24 & 2.22 \\
$\begin{array}{l}\text { Heat of } \\
\text { combustion }\end{array}$ & $\mathrm{MJ} / \mathrm{kg}$ & 44.79 & 47.97 & 47.91 & 47.68 & 47.97 & 47.88 \\
\hline
\end{tabular}

* refers to 2,2,4-trimethyl pentane;

Table 13

FACE F gasoline: comparison of MFG surrogate with multicomponent surrogates reported in literature

\begin{tabular}{|c|c|c|c|c|c|c|c|}
\hline $\begin{array}{l}\text { Functional } \\
\text { groups }\end{array}$ & unit & $\begin{array}{l}\text { FACE } \\
\text { gasoline }\end{array}$ & MFG surrogate & $\begin{array}{l}\text { Mannaa et al } \\
\text { [92] }\end{array}$ & $\begin{array}{l}\text { Sarathy } \\
\text { et al [69] }\end{array}$ & $\begin{array}{l}\text { Sarathy } \\
\text { et al [69] }\end{array}$ & $\begin{array}{l}\text { Sarathy } \\
\text { et al [69] }\end{array}$ \\
\hline & & & $\begin{array}{l}\text { 3-methyl pentane } \\
\text { indane }\end{array}$ & $\begin{array}{l}\text { n-heptane } \\
\text { iso-octane* } \\
\text { toluene }\end{array}$ & $\begin{array}{l}n \text {-heptane } \\
\text { iso-octane* } \\
\text { toluene }\end{array}$ & $\begin{array}{l}n \text {-butane } \\
n \text {-heptane } \\
\text { iso-octane* } \\
\text { 1-hexene } \\
\text { cyclo-pentane } \\
\text { toluene }\end{array}$ & $\begin{array}{l}\text { n-butane } \\
\text { 2-methyl butane } \\
\text { 2-methyl hexane } \\
\text { iso-octane } \\
\text { 1-hexene } \\
\text { cyclo-pentane } \\
\text { 1,2,4-TMB }\end{array}$ \\
\hline density & $\mathrm{g} / \mathrm{ml}$ & 0.71 & 0.75 & 0.69 & 0.74 & 0.71 & 0.70 \\
\hline average $\mathrm{MW}$ & $\mathrm{g} / \mathrm{mol}$ & 95.6 & 92.4 & 111.98 & 103.69 & 100.02 & 96.07 \\
\hline $\mathrm{H} / \mathrm{C}$ ratio & molar & 2.12 & 2 & 2.20 & 1.84 & 2.06 & 2.10 \\
\hline $\begin{array}{l}\text { Heat of } \\
\text { combustion }\end{array}$ & $\mathrm{MJ} / \mathrm{kg}$ & 44.36 & 44.05 & 47.66 & 46.01 & 47.21 & 47.43 \\
\hline
\end{tabular}

* refers to 2,2,4-trimethyl pentane; \# refers to 1,2,4-trimethyl benzene;

Table 14

FACE G gasoline: comparison of MFG surrogate with multicomponent surrogates reported in literature

\begin{tabular}{|c|c|c|c|c|c|c|c|}
\hline $\begin{array}{l}\text { Functional } \\
\text { groups }\end{array}$ & unit & $\begin{array}{l}\text { FACE } \\
\text { gasoline }\end{array}$ & $\begin{array}{l}\text { MFG surrogate } \\
\left(\mathrm{S}_{1}\right)\end{array}$ & $\begin{array}{l}\text { MFG surrogate } \\
\left(S_{2}\right)\end{array}$ & $\begin{array}{l}\text { Sarathy } \\
\text { et al [69] }\end{array}$ & $\begin{array}{l}\text { Sarathy } \\
\text { et al [69] }\end{array}$ & $\begin{array}{l}\text { Sarathy et al } \\
\text { [69] }\end{array}$ \\
\hline & & & $\begin{array}{l}\text { 3-methyl pentane } \\
\text { tetralin }\end{array}$ & $\begin{array}{l}\text { 3-methyl pentane } \\
\text { tetralin }\end{array}$ & $\begin{array}{l}n \text {-heptane } \\
\text { iso-octane* } \\
\text { toluene }\end{array}$ & $\begin{array}{l}\text { n-heptane } \\
\text { iso-octane* } \\
\text { 1-hexene } \\
\text { cyclo-pentane } \\
\text { 1,2,4-TMB }\end{array}$ & $\begin{array}{l}\text { n-butane } \\
\text { 2-methyl butane } \\
\text { 2-methyl hexane } \\
\text { iso-octane* } \\
\text { 1-hexene } \\
\text { cyclo-pentane } \\
\text { toluene } \\
1,2,4-M^{*} B^{\#}\end{array}$ \\
\hline density & $\mathrm{g} / \mathrm{ml}$ & 0.76 & 0.79 & 0.78 & 0.81 & 0.75 & 0.74 \\
\hline $\begin{array}{l}\text { average } \\
\mathrm{MW}\end{array}$ & $\mathrm{g} / \mathrm{mol}$ & 98.97 & 100.64 & 100 & 94.65 & 105.88 & 94.15 \\
\hline $\mathrm{H} / \mathrm{C}$ ratio & molar & 1.84 & 1.83 & 1.82 & 1.40 & 1.87 & 1.82 \\
\hline $\begin{array}{l}\text { Heat of } \\
\text { combustion }\end{array}$ & $\mathrm{MJ} / \mathrm{kg}$ & 43.26 & 45.62 & 45.79 & 43.85 & 46.19 & 46.14 \\
\hline
\end{tabular}

\footnotetext{
* refers to 2,2,4-trimethyl pentane; \# refers to 1,2,4-trimethyl benzene;
} 
[Type text]

Table 15

FACE I gasoline: comparison of MFG surrogate with multicomponent surrogates reported in literature

\begin{tabular}{|c|c|c|c|c|c|c|}
\hline $\begin{array}{l}\text { Functional } \\
\text { groups }\end{array}$ & unit & $\begin{array}{l}\text { FACE } \\
\text { gasoline }\end{array}$ & MFG surrogate & $\begin{array}{l}\text { Bhavanishankar } \\
\text { et al [30] }\end{array}$ & $\begin{array}{l}\text { Javed } \\
\text { et al [93] }\end{array}$ & $\begin{array}{l}\text { Elwardany } \\
\text { et al [94] }\end{array}$ \\
\hline & & & 3-methyl pentane & $\begin{array}{l}\text { n-heptane } \\
\text { iso-octane* }\end{array}$ & $\begin{array}{l}\text { 2-methyl butane } \\
\text { 2-methyl hexane } \\
\text { n-heptane } \\
\text { iso-octane* } \\
\text { 1-hexene } \\
\text { cyclo-pentane } \\
1,2,4-T M B^{\#}\end{array}$ & $\begin{array}{l}\text { 2-methyl butane } \\
\text { 2-methyl hexane } n \text { - } \\
\text { heptane } \\
\text { iso-octane* } \\
\text { 2,3,4-trimethyl pentane } \\
\text { 1-hexene } \\
\text { Methyl-cyclohexane } \\
\text { toluene }\end{array}$ \\
\hline density & $\mathrm{g} / \mathrm{ml}$ & 0.69 & 0.66 & 0.69 & 0.68 & 0.68 \\
\hline average $\mathrm{MW}$ & $\mathrm{g} / \mathrm{mol}$ & 95.44 & 86 & 109.41 & 99.72 & 96.54 \\
\hline $\mathrm{H} / \mathrm{C}$ ratio & molar & 2.26 & 2.33 & 2.26 & 2.12 & 2.21 \\
\hline $\begin{array}{l}\text { Heat of } \\
\text { combustion }\end{array}$ & $\mathrm{MJ} / \mathrm{kg}$ & 44.71 & 48.2 & 47.94 & 47.77 & 47.79 \\
\hline
\end{tabular}

Table 16

FACE J gasoline: comparison of MFG surrogate with multicomponent surrogates reported in literature

\begin{tabular}{|c|c|c|c|c|c|c|}
\hline $\begin{array}{l}\text { Functional } \\
\text { groups }\end{array}$ & unit & $\begin{array}{l}\text { FACE } \\
\text { gasoline }\end{array}$ & MFG surrogate & $\begin{array}{l}\text { Bhavanishankar } \\
\text { et al [30] }\end{array}$ & $\begin{array}{l}\text { Mannaa et al } \\
\text { [92] }\end{array}$ & Javed et al [93] \\
\hline & & & $\begin{array}{l}n \text {-heptane } \\
\text { toluene }\end{array}$ & $\begin{array}{l}\text { n-heptane } \\
\text { iso-octane* }\end{array}$ & $\begin{array}{l}n \text {-heptane } \\
\text { iso-octane* } \\
\text { toluene }\end{array}$ & $\begin{array}{l}n \text {-butane } \\
\text { 2-methyl hexane } \\
n \text {-heptane } \\
\text { iso-octane* } \\
1,2,4-\text { TMB }^{\#}\end{array}$ \\
\hline density & $\mathrm{g} / \mathrm{ml}$ & 0.74 & 0.76 & 0.69 & 0.74 & 0.73 \\
\hline average $\mathrm{MW}$ & $\mathrm{g} / \mathrm{mol}$ & 94.5 & 96.22 & 109.41 & 99.31 & 103.27 \\
\hline $\mathrm{H} / \mathrm{C}$ ratio & molar & 1.86 & 1.75 & 2.26 & 1.83 & 1.88 \\
\hline $\begin{array}{l}\text { Heat of } \\
\text { combustion }\end{array}$ & $\mathrm{MJ} / \mathrm{kg}$ & 43.56 & 43.35 & 47.94 & 45.99 & 46.47 \\
\hline
\end{tabular}

* refers to 2,2,4-trimethyl pentane; \# refers to 1,2,4-trimethyl benzene;

\subsection{IQT ignition delay times}

Ignition delay times (IDT) of the FACE gasolines and their respective MFG surrogates were experimentally determined to validate the surrogates, and hence the validity of the MFG approach. Pressure traces of all the FACE gasoline fuels and their surrogates along with their total ignition delay times are shown in Fig. 5. The time of injection (Solnj) and time of ignition (Solgn) are also shown in Fig. 5 . It is observed that the MFG surrogates have similar reactivity to their 
respective target gasoline, as indicated by similar total IDT. Differences in total IDT for all FACE gasolines and their respective MFG surrogates are less than $10 \%$. FACE G surrogate 1, which has more paraffinic groups compared to FACE G surrogate 2, matches the paraffinic content of the fuel more closely and also reproduces the ignition behavior of the fuel more closely. This shows the IDT (at low temperatures) emulation depends more on paraffinic groups, especially paraffinic $\mathrm{CH}_{2}$ groups, as previously indicated by Won et al. [39].

The DCN of the FACE gasolines and their MFG surrogates were also evaluated from the knowledge of the IDT. Two equations are utilized to calculate the DCN depending on the range of the IDT; Eq. (12) is used when IDT is in the range of 3.1- $6.5 \mathrm{~ms}$ while Eq. (13) is utilized for other values of IDT.

$D C N=4.46+\left(\frac{186.6}{\mathrm{IDT}}\right)$

$D C N=83.99\left[(\text { IDT }-1.512)^{-0.658}\right]+3.547$

The DCN values determined for the FACE gasolines and their respective MFG surrogates are reported in Table 17 and lie in the range $(<35)$ associated with gasoline fuels. The DCN of the MFG surrogates for FACE C, F, G, I and J match closely with the target gasolines (difference $<5$ $\%)$, while the DCN for FACE A MFG surrogate shows a difference of $\approx 7 \%$. The FACE G surrogate 1 which better matches the paraffinic content in the fuel compared to surrogate 2 also matches the DCN more closely. The heat release rates of FACE gasolines and their respective MFG surrogate fuels are shown in Fig. S2 in Supplementary Material.

\section{Table 17}

Comparison of DCN values of FACE gasoline fuels and their surrogates

\begin{tabular}{lll}
\hline Name & \multicolumn{2}{c}{ DCN (no unit) } \\
\cline { 2 - 3 } & Fuel & Surrogate \\
\hline FACE A & 26.4 & 28.2 \\
FACE C & 26.5 & 27.5 \\
FACE F & 19.5 & 19.9 \\
FACE G & 18.0 & $18.4\left(\mathrm{~S}_{1}\right)$
\end{tabular}


FACE I $\quad 31.7 \quad 30.7$

FACE J $\quad 29.7 \quad 31.0$

$S_{1}$ and $S_{2}$ refer to surrogates $1 \& 2$, respectively.

\subsection{Rapid compression machine}

Fig. 6 shows the comparison of the ignition delays of the FACE gasolines and their respective MFG surrogates. The FACE I and J gasolines possess the lowest Anti-Knock Index (AKI) of $\sim 70$ amongst the fuels investigated here and exhibit the shortest ignition delay, followed by FACE $A$ and $C$ gasoline (AKI $~ 84)$ and then FACE F and $G(A K I \sim 92)$.

The RCM measurements show that high octane fuels exhibit longer ignition delay times compared to low octane fuels as expected. FACE A and C, which are fairly similar in regards to their composition, exhibit similar ignition delay characteristics, and the one component MFG surrogate (2,4-dimethylpentane) with an AKI of 83.4 [108] does well to capture the overall reactivity of FACE A. FACE I and J gasolines are compositionally very different, but have similar ignition delay behavior, as shown by the RCM measurements. FACE I is rich in paraffins (similar to FACE A and C) whereas FACE J possesses considerable aromatics (32.5 wt \%). FACE F and G gasolines are less reactive compared to the other fuels and clearly exhibit a Negative Temperature Co-efficient (NTC) regime between the temperatures of $740-833 \mathrm{~K}$. FACE F contains higher paraffinic content and has a greater negative slope in the NTC regime compared to FACE G, characteristic of fuels with lower octane sensitivity [69]. All the formulated MFG surrogates replicate the ignition behavior of the target fuels, except the FACE G surrogates. This could be because of the high compositional diversity of FACE G gasoline, as it contains appreciable quantities of all different functional groups; this poses a challenge in formulating the surrogate with the MFG approach. FACE G Surrogate 1 replicates the functional groups more closely than Surrogate 2, and hence has an ignition behavior closer to that of the target fuel.

Fig. 7 shows measured pressure traces of FACE gasolines and their respective MFG surrogates at various temperatures. FACE $A$ and $C$ gasolines show single stage ignition at 644 and 
[Type text]

$670 \mathrm{~K}$, and these fuels exhibit two stage ignition above $700 \mathrm{~K}$. The surrogates, however, show two stage ignition below $700 \mathrm{~K}$. FACE F and G show two stage ignition at temperatures lower than $750 \mathrm{~K}$. A higher pressure rise is observed in the first stage for FACE F compared to FACE G due to greater LTHR. The surrogates for FACE F and G successfully reproduce the two-stage ignition response observed in the respective fuels, but the pressure trace comparison for FACE F shows a slight discrepancy. This is because both the FACE F and G surrogates contain slightly less paraffinic $\mathrm{CH}_{3}$ groups than the fuels, and these groups have been shown to have a greater impact on the evolution of ignition processes [49,100]. FACE I and J and their MFG surrogates do not exhibit two-stage ignition in the temperature ranges studied in the RCM.

\subsection{Smoke Point and Threshold Sooting Index}

The smoke point, virtual smoke point and threshold sooting index of the FACE gasoline fuels and their respective MFG surrogates along with uncertainties are presented in Table 18. Experimental data used to derive the virtual smoke point for FACE A, C and I gasolines are presented in Fig. 8 and 2,4-dimethylpentane (surrogate for FACE A), 3-methylpentane-tetralin 94/6 wt \% (surrogate for FACE C) and 3-methylpentane (surrogate for FACE I) are presented in Fig. 9. The threshold sooting index and smoke point/virtual smoke point values of FACE A, C and G match very well with their respective MFG surrogates, which indicate similar sooting propensity. Two different surrogates of FACE G were formulated, i.e. surrogate 1 and 2 . The proportion of aromatic C-CH group in surrogate 2 is closer to FACE G compared to surrogate 1, which can explain the better results obtained for the smoke point and threshold sooting index. Those results shows that the aromatic $\mathrm{C}-\mathrm{CH}$ groups have a more pronounced effect on smoke point and threshold sooting index, whereas the paraffinic groups have a more pronounced effect on the ignition delay time as shown by the IQT measurements of surrogate 1 . Results obtained for FACE I and J present differences that are within the uncertainty boundaries, albeit the uncertainties are significant and largely attributed to the uncertainty in the linear extrapolation. FACE $F$ and its surrogates present very different smoke point and threshold sooting index, which indicate different sooting propensity. This may be explained by the FACE F surrogate having 
[Type text]

approximately $25 \%$ more aromatic groups compared to FACE F gasoline which again reiterates the importance of aromatic groups on smoke point and threshold sooting index.

\section{Table 18}

(Virtual) Smoke point and threshold sooting index of FACE gasolines and their respective MFG surrogates.

\begin{tabular}{|c|c|c|c|c|c|c|c|}
\hline Fuel & $\begin{array}{l}\text { Molecular } \\
\text { weight } \\
\text { (g/mol) }\end{array}$ & $\begin{array}{l}\text { (Virtual) } \\
\text { Smoke Point } \\
\quad(\mathrm{mm})\end{array}$ & $\begin{array}{l}\text { Threshold } \\
\text { Sooting } \\
\text { Index }\end{array}$ & Surrogate & $\begin{array}{l}\text { Molecular } \\
\text { weight } \\
\text { (g/mol) }\end{array}$ & $\begin{array}{c}\text { Virtual } \\
\text { Smoke } \\
\text { Point } \\
(\mathrm{mm})\end{array}$ & $\begin{array}{c}\text { Threshold } \\
\text { Sooting Index }\end{array}$ \\
\hline FACE A & $99.78 \pm 5.0$ & $67.9 \pm 18.7$ & $2.2 \pm 1.7$ & 2,4-dimethylpentane & 100.2 & $66.6 \pm 15.3$ & $2.4 \pm 1.4$ \\
\hline FACE C & $97.71 \pm 5.0$ & $49.8 \pm 4.8$ & $4.4 \pm 1.2$ & 3-methylpentane/Tetralin (94/6 mol \%) & 88 & $44.8 \pm 3.3$ & $4.3 \pm 0.6$ \\
\hline FACE F & $95.60 \pm 5.0$ & $37.4 \pm 1.0$ & $6.6 \pm 1.5$ & 3-methylpentane/Indane (80/20 mol \%) & 92.6 & $18.4 \pm 1.0$ & $16.8 \pm 1.6$ \\
\hline FACE G & $98.97 \pm 20.0$ & $15.6 \pm 1.0$ & $22.1 \pm 13.5$ & $\begin{array}{l}\text { 3-methylpentane/Tetralin (70/30 mol \%), } \mathrm{S}_{1} \\
\text { 3-methylpentane/Tetralin (68/32 mol \%), } \mathrm{S}_{2}\end{array}$ & $\begin{array}{l}100.6 \\
100.0\end{array}$ & $\begin{array}{l}14.4 \pm 1.0 \\
15.0 \pm 1.0\end{array}$ & $\begin{array}{l}25.2 \pm 0.7 \\
23.8 \pm 0.7\end{array}$ \\
\hline FACE I & $95.44 \pm 5.0$ & $102.1 \pm 56.9$ & $0.2 \pm 2.0$ & 3-methylpentane & 86.2 & $64.4 \pm 14.1$ & $1.7 \pm 1.2$ \\
\hline FACE J & $94.50 \pm 20.0$ & $18.0 \pm 1.0$ & $17.7 \pm 11.5$ & n-heptane/Toluene (53/47 mol \%) & 96.4 & $18.8 \pm 1.0$ & $15.3 \pm 1.5$ \\
\hline
\end{tabular}

$S_{1}$ and $S_{2}$ refers to surrogate $1 \& 2$, respectively.

Fig. 10 represents the threshold sooting index vs carbon ratio of the FACE gasoline fuels and their respective MFG surrogates. Data of the carbon ratio of the FACE gasoline fuels were taken from the $\mathrm{CRC}$ report [40], while the carbon ratio of the respective surrogates was calculated from the known composition. For FACE A, C and $\mathrm{G}$ the carbon ratio and TSI values were similar with their respective MFG surrogates, which can explain similar sooting propensity between the FACE fuel gasoline and respective MFG surrogates. For FACE I and J, the values of the carbon ratio show clear difference but the TSI values are within the uncertainty boundaries, which can explain the difference in sooting propensities. FACE F and its surrogate show a similar carbon ratio while the value of the TSI is different and out of the uncertainty boundary. 


\section{CONCLUSION}

This work presented a novel minimalist functional group (MFG) methodology to formulate surrogates of six FACE gasoline fuels (namely FACE A, C, F, G, I and J) by matching five functional groups and the Branching Index present in the FACE gasolines. High-resolution ${ }^{1} \mathrm{H} N M R$ spectroscopy was used to identify and quantify the functional groups and $\mathrm{BI}$ of the target fuels. The number of surrogate species chosen to represent each FACE gasoline was kept to a maximum of two components (albeit the MFG approach could also use a single component). Physical (e.g., density and average molecular weight) and chemical (e.g., $\mathrm{H} / \mathrm{C}$ ratio and heats of combustion) properties of the FACE gasolines matched well with those of the respective MFG surrogates. The surrogates were experimentally validated using IDT measured in an IQT, and similar values were obtained for the MFG surrogates and their target fuels. RCM measurements were made at 20 bar and at stoichiometric conditions and the surrogates were successful in mimicking the ignition behaviour of the FACE gasolines, except for FACE G surrogates which exhibited some discrepancy. The values of the smoke point (SP)/virtual smoke point (VSP), threshold sooting index (TSI) and carbon ratio show that the properties of FACE A, C and G gasolines match well with their respective MFG surrogates. FACE I and J gasolines show compatible SP/VSP and TSI value, but the carbon ratio shows significant differences.

These results show the importance of different functional groups for replicating a variety of combustion relevant phenomenon (e.g., ignition delay, sooting index, etc.). The MFG surrogates also closely matched the $\mathrm{BI}$ term for most of the real fuels; however, further research is required to determine how accurately the $\mathrm{BI}$ needs to be matched to emulate important combustion properties. Overall, the present MFG approach confirms the hypothesis that the functional groups in a fuel can be utilized as a fundamental target property to formulate surrogates.

In addition to conventional surrogate fuel formulation and kinetic model reduction methods $[8,15,109]$ the MFG approach presents another way of constraining the size of surrogate fuel mixture formulations and resulting chemical kinetic models. This may simplify the surrogate 
formulation and testing procedure, while reducing incurred time and cost. From a purely numerical perspective, the MFG approach suggests that a hypothetical chemical structure can be developed to match the functional groups and BI of a target fuel. The MFG surrogate can be used to calculate physical and chemical properties, develop chemical kinetic models, and perform engine simulations. Complex engine processes such as liquid spray formation, droplet breakup, and multi-component evaporation could be simulated using more complex multicomponent physical surrogates, as already routinely done in the literature [110-113]. From an experimental perspective, hypothetical surrogate molecules may not be readily available for testing. The availability of data for validating the surrogate and kinetic models would become increasingly expensive for exotic MFG surrogate molecules. For this reason, we selected MFG surrogates that were available to purchase for experimental testing. The MFG approach presents to engineers with another way to formulate surrogate fuels, which complements other recent methods, such as physical surrogate group chemistry representation (PSGCR) [109] combustion property targets [39] with experimental uncertainty [114], and the HyChem physics-based approach $[115,116]$. The MFG approach can also be extended to develop surrogates for other complex fuel mixtures, such as diesel fuel, aviation fuel, and heavy and crude oils.

\section{Acknowledgements}

This work was supported by Saudi Aramco under the FUELCOM Program and by King Abdullah University of Science and Technology (KAUST). The work was also funded by KAUST competitive research funding awarded to the Clean Combustion Research Center. Work at Trinity College Dublin is supported by competitive research funding from King Abdullah University of Science and Technology (KAUST) and by Science Foundation Ireland under 13/SIRG/2185(X) and 16/ERCD/3685.

\section{References}

[1] S.M. Sarathy, A. Farooq, G.T. Kalghatgi, Recent progress in gasoline surrogate fuels, Prog. Energy Combust. Sci. 65 (2018) 67-108.

[2] W.J. Pitz, C.J. Mueller, Recent progress in the development of diesel surrogate fuels, Prog. Energy Combust. Sci. 37 (2011) 330-350.

[3] A. Ahmed, G. Goteng, V.S.B. Shankar, K. Al-Qurashi, W.L. Roberts, S.M. Sarathy, A computational methodology for formulating gasoline surrogate fuels with accurate physical and chemical kinetic 
[Type text]

properties, Fuel. 143 (2015) 290-300.

[4] P.L. Perez, A.L. Boehman, Experimental Investigation of the Autoignition Behavior of Surrogate Gasoline Fuels in a Constant-Volume Combustion Bomb Apparatus and Its Relevance to $\mathrm{HCCl}$ Combustion, Energy \& Fuels. 26 (2012) 6106-6117.

[5] K.E. Niemeyer, C.-J. Sung, Reduced Chemistry for a Gasoline Surrogate Valid at Engine-Relevant Conditions, Energy \& Fuels. 29 (2015) 1172-1185.

[6] C. Pera, V. Knop, Methodology to define gasoline surrogates dedicated to auto-ignition in engines, Fuel. 96 (2012) 59-69.

[7] B.J. Zhong, D. Zheng, A chemical mechanism for ignition and oxidation of multi-component gasoline surrogate fuels, Fuel. 128 (2014) 458-466.

[8] M. Mehl, J.Y. Chen, W.J. Pitz, S.M. Sarathy, C.K. Westbrook, An Approach for Formulating Surrogates for Gasoline with Application toward a Reduced Surrogate Mechanism for CFD Engine Modeling, Energy \& Fuels. 25 (2011) 5215-5223.

[9] P.L. Perez, A.L. Boehman, Effects of the Chemical Structure and Composition of Surrogate Gasoline Fuels on Homogeneous Charge Compression Ignition Combustion in a Single-Cylinder Engine, Energy \& Fuels. 28 (2014) 3377-3390.

[10] M. Su, C.P. Chen, Heating and evaporation of a new gasoline surrogate fuel: A discrete multicomponent modeling study, Fuel. 161 (2015) 215-221.

[11] A.E. Elwardany, S.S. Sazhin, H.G. Im, A new formulation of physical surrogates of FACE A gasoline fuel based on heating and evaporation characteristics, Fuel. 176 (2016) 56-62.

[12] T.M. Foong, K.J. Morganti, M.J. Brear, G. da Silva, Y. Yang, F.L. Dryer, The octane numbers of ethanol blended with gasoline and its surrogates, Fuel. 115 (2014) 727-739.

[13] J.L. Burger, M.E. Harries, T.J. Bruno, Characterization of Four Diesel Fuel Surrogates by the Advanced Distillation Curve Method, Energy \& Fuels. 30 (2016) 2813-2820.

[14] H.M. Poon, K.M. Pang, H.K. Ng, S. Gan, J. Schramm, Development of multi-component diesel surrogate fuel models - Part I: Validation of reduced mechanisms of diesel fuel constituents in 0D kinetic simulations, Fuel. 180 (2016) 433-441.

[15] Y. Chang, M. Jia, Y. Li, Y. Liu, M. Xie, H. Wang, R.D. Reitz, Development of a skeletal mechanism for diesel surrogate fuel by using a decoupling methodology, Combust. Flame. 162 (2014) 37853802.

[16] R. Payri, J.P. Viera, Y. Pei, S. Som, Experimental and numerical study of lift-off length and ignition delay of a two-component diesel surrogate, Fuel. 158 (2015) 957-967.

[17] K. Anand, Y. Ra, R.D. Reitz, B. Bunting, Surrogate Model Development for Fuels for Advanced Combustion Engines, Energy \& Fuels. 25 (2011) 1474-1484.

[18] S. Dooley, S.H. Won, M. Chaos, J. Heyne, Y. Ju, F.L. Dryer, K. Kumar, C.-J. Sung, H. Wang, M.A. Oehlschlaeger, R.J. Santoro, T.A. Litzinger, A jet fuel surrogate formulated by real fuel properties, Combust. Flame. 157 (2010) 2333-2339.

[19] S. Dooley, S.H. Won, S. Jahangirian, Y. Ju, F.L. Dryer, H. Wang, M.A. Oehlschlaeger, The combustion kinetics of a synthetic paraffinic jet aviation fuel and a fundamentally formulated, experimentally validated surrogate fuel, Combust. Flame. 159 (2012) 3014-3020. 
[Type text]

[20] J. Yu, Z. Wang, X. Zhuo, W. Wang, X. Gou, Surrogate Definition and Chemical Kinetic Modeling for Two Different Jet Aviation Fuels, Energy \& Fuels. (2016) acs.energyfuels.5b02414.

[21] D. Kim, J. Martz, A. Violi, A surrogate for emulating the physical and chemical properties of conventional jet fuel, Combust. Flame. 161 (2014) 1489-1498.

[22] K. Narayanaswamy, H. Pitsch, P. Pepiot, A component library framework for deriving kinetic mechanisms for multi-component fuel surrogates: Application for jet fuel surrogates, Combust. Flame. 165 (2016) 288-309.

[23] S. Dooley, S.H. Won, J. Heyne, T.I. Farouk, Y. Ju, F.L. Dryer, K. Kumar, X. Hui, C.J. Sung, H. Wang, M.A. Oehlschlaeger, V. Iyer, S. Iyer, T.A. Litzinger, R.J. Santoro, T. Malewicki, K. Brezinsky, The experimental evaluation of a methodology for surrogate fuel formulation to emulate gas phase combustion kinetic phenomena, Combust. Flame. 159 (2012) 1444-1466.

[24] Z. Li, W. Wang, Z. Huang, M.A. Oehlschlaeger, Autoignition of methyl decanoate, a biodiesel surrogate, under high-pressure exhaust gas recirculation conditions, Energy and Fuels. 26 (2012) 4887-4895.

[25] S. Dooley, H.J. Curran, J.M. Simmie, Autoignition measurements and a validated kinetic model for the biodiesel surrogate, methyl butanoate, Combust. Flame. 153 (2008) 2-32.

[26] O. Herbinet, W.J. Pitz, C.K. Westbrook, Detailed chemical kinetic oxidation mechanism for a biodiesel surrogate, Combust. Flame. 154 (2008) 507-528.

[27] S. Gaïl, S.M. Sarathy, M.J. Thomson, P. Diévart, P. Dagaut, Experimental and chemical kinetic modeling study of small methyl esters oxidation: Methyl (E)-2-butenoate and methyl butanoate, Combust. Flame. 155 (2008) 635-650.

[28] S. Gail, M.J. Thomson, S.M. Sarathy, S.A. Syed, P. Dagaut, P. Di??vart, A.J. Marchese, F.L. Dryer, A wide-ranging kinetic modeling study of methyl butanoate combustion, Proc. Combust. Inst. 31 I (2007) 305-311.

[29] A.G. Abdul Jameel, A.M. Elbaz, A.-H. Emwas, W.L. Roberts, S.M. Sarathy, Calculation of Average Molecular Parameters, Functional Groups, and a Surrogate Molecule for Heavy Fuel Oils Using 1 H and 13 C Nuclear Magnetic Resonance Spectroscopy, Energy \& Fuels. 30 (2016) 3894-3905.

[30] V.S. Bhavani Shankar, M. Sajid, K. Al-Qurashi, N. Atef, I. Alkhesho, A. Ahmed, S. Chung, W. Roberts, K. Morganti, M. Sarathy, Primary Reference Fuels (PRFs) as Surrogates for Low Sensitivity Gasoline Fuels, in: SAE Tech. Pap. 2016-01-0748, 2016.

[31] ASTM Int., Standard Test Method for Research Octane Number of Spark-Ignition Engine Fuel 1, 2012.

[32] ASTM Int., Standard Test Method for Motor Octane Number of Spark-Ignition Engine Fuel 1, 2011.

[33] A.T. Holley, X.Q. You, E. Dames, H. Wang, F.N. Egolfopoulos, Sensitivity of propagation and extinction of large hydrocarbon flames to fuel diffusion, Proc. Combust. Inst. 32 (2009) 11571163.

[34] S.H. Won, S. Dooley, F.L. Dryer, Y. Ju, A radical index for the determination of the chemical kinetic contribution to diffusion flame extinction of large hydrocarbon fuels, Combust. Flame. 159 (2012) 541-551.

[35] C.J. Mueller, W.J. Cannella, T.J. Bruno, B. Bunting, H.D. Dettman, J.A. Franz, M.L. Huber, M. 
[Type text]

Natarajan, W.J. Pitz, M.A. Ratcliff, K. Wright, Methodology for Formulating Diesel Surrogate Fuels with Accurate Compositional, Ignition-Quality, and Volatility Characteristics, Energy \& Fuels. 26 (2012) 3284-3303.

[36] S.M. Sarathy, G. Kukkadapu, M. Mehl, W. Wang, T. Javed, S. Park, M.A. Oehlschlaeger, A. Farooq, W.J. Pitz, C.-J. Sung, Ignition of alkane-rich FACE gasoline fuels and their surrogate mixtures, Proc. Combust. Inst. 35 (2015) 249-257.

[37] A. Violi, S. Yan, E.G. Eddings, A.F. Sarofim, S. Granata, T. Faravelli, E. Ranzi, Experimental formulation and kinetic model for JP-8 surrogate mixtures, Combust. Sci. Technol. 174 (2002) 399-417.

[38] Y. Yang, A.L. Boehman, R.J. Santoro, A study of jet fuel sooting tendency using the threshold sooting index (TSI) model, Combust. Flame. 149 (2007) 191-205.

[39] S.H. Won, F.M. Haas, S. Dooley, T. Edwards, F.L. Dryer, Reconstruction of chemical structure of real fuel by surrogate formulation based upon combustion property targets, Combust. Flame. 183 (2017) 39-49.

[40] W.J. Cannella, M. Foster J, G. Gunter, W. Leppard, CRC Report No . AVFL-24 Face gasolines and blends with ethanol: Detailed characterization of physical and chemical properties, 2014.

[41] H. Yuan, B. Yang, J. Yang, Predicting Properties of Biodiesel Fuels using Mixture Topological Index, 2009. doi:10.1007/s11746-009-1354-y.

[42] T. Thuy, D. Allen, Property estimation using structural characterizationsHeat capacities of coal liquids, Fuel. 64 (1985) 1754-1759.

[43] S.W. Benson, F.R. Cruickshank, D.M. Golden, G.R. Haugen, H.E. O'Neal, a S. Rodgers, R. Shaw, R. Walsh, Additivity rules for the estimation of thermochemical properties, Chem. Rev. 69 (1969) 279-324.

[44] D.A. Saldana, L. Starck, P. Mougin, B. Rousseau, L. Pidol, N. Jeuland, B. Creton, Flash Point and Cetane Number Predictions for Fuel Compounds Using Quantitative Structure Property Relationship (QSPR) Methods, Energy \& Fuels. 25 (2011) 3900-3908.

[45] B. Creton, C. Dartiguelongue, T. de Bruin, H. Toulhoat, Prediction of the Cetane Number of Diesel Compounds Using the Quantitative Structure Property Relationship, Energy \& Fuels. 24 (2010) 5396-5403.

[46] A.G. Abdul Jameel, N. Naser, A.-H. Emwas, S. Dooley, S.M. Sarathy, Predicting Fuel Ignition Quality Using 1 H NMR Spectroscopy and Multiple Linear Regression, Energy \& Fuels. 30 (2016) 9819-9835.

[47] S.H. Won, S. Dooley, P.S. Veloo, H. Wang, M.A. Oehlschlaeger, F.L. Dryer, Y. Ju, The combustion properties of 2,6,10-trimethyl dodecane and a chemical functional group analysis, Combust. Flame. 161 (2014) 826-834.

[48] S.M. Heck, H.O. Pritchard, J.F. Griffiths, Cetane number vs. structure in paraffin hydrocarbons, J. Chem. Soc. Faraday Trans. 94 (1998) 1725-1727.

[49] M. Lapuerta, J.J. Hernández, S.M. Sarathy, Effects of methyl substitution on the auto-ignition of C16 alkanes, Combust. Flame. 164 (2016) 259-269.

[50] E.J. Silke, H.J. Curran, J.M. Simmie, The influence of fuel structure on combustion as demonstrated by the isomers of heptane: a rapid compression machine study, Proc. Combust. 
[Type text]

Inst. 30 (2005) 2639-2647.

[51] J. Hernández-Trujillo, R.F.W. Bader, Properties of Atoms in Molecules: Atoms Forming Molecules, J. Phys. Chem. A. 104 (2000) 1779-1794.

[52] R. Sumathi, H.-H. Carstensen, W.H. Green, Reaction Rate Prediction via Group Additivity Part 1: H Abstraction from Alkanes by H and CH 3, J. Phys. Chem. A. 105 (2001) 6910-6925.

[53] R. Sumathi, H.-H. Carstensen, W.H. Green, Reaction Rate Prediction via Group Additivity, Part 2: $\mathrm{H}$-Abstraction from Alkenes, Alkynes, Alcohols, Aldehydes, and Acids by H Atoms, J. Phys. Chem. A. 105 (2001) 8969-8984.

[54] R. Sumathi, H. Carstensen, W.H. Green, Reaction Rate Predictions Via Group Additivity. Part 3: Effect of Substituents with CH 2 as the Mediator, J. Phys. Chem. A. 106 (2002) 5474-5489..

[55] P. Pepiotdesjardins, H. Pitsch, R. Malhotra, S. Kirby, A. Boehman, Structural group analysis for soot reduction tendency of oxygenated fuels, Combust. Flame. 154 (2008) 191-205.

[56] M. Mehl, W.J. Pitz, S.M. Sarathy, C.K. Westbrook, Modeling the combustion of high molecular weight fuels by a functional group approach, Int. J. Chem. Kinet. 44 (2012) 257-276.

[57] A. Marongiu, T. Faravelli, G. Bozzano, M. Dente, E. Ranzi, Thermal degradation of poly(vinyl chloride), J. Anal. Appl. Pyrolysis. 70 (2003) 519-553.

[58] M. Mehl, A. Marongiu, T. Faravelli, G. Bozzano, M. Dente, E. Ranzi, A kinetic modeling study of the thermal degradation of halogenated polymers, J. Anal. Appl. Pyrolysis. 72 (2004) 253-272.

[59] R.J. Quann, S.B. Jaffe, Structure-oriented lumping: describing the chemistry of complex hydrocarbon mixtures, Ind. Eng. Chem. Res. 31 (1992) 2483-2497.

[60] S. Yan, E.G. Eddings, A.B. Palotas, R.J. Pugmire, A.F. Sarofim, Prediction of Sooting Tendency for Hydrocarbon Liquids in Diffusion Flames, Energy \& Fuels. 19 (2005) 2408-2415.

[61] E.J. Barrientos, M. Lapuerta, A.L. Boehman, Group additivity in soot formation for the example of C-5 oxygenated hydrocarbon fuels, Combust. Flame. 160 (2013) 1484-1498.

[62] J. Yu, Y. Ju, X. Gou, Surrogate fuel formulation for oxygenated and hydrocarbon fuels by using the molecular structures and functional groups, Fuel. 166 (2016) 211-218.

[63] K. V Puduppakkam, L. Liang, C. V Naik, E. Meeks, S.L. Kokjohn, R.D. Reitz, Use of Detailed Kinetics and Advanced Chemistry-Solution Techniques in CFD to Investigate Dual-Fuel Engine Concepts, SAE Int. J. Engines. 4 (2011) 2011-01-0895.

[64] J.C.G. Andrae, P. Bjornbom, R.F. Cracknell, G.T. Kalghatgi, Autoignition of toluene reference fuels at high pressures modeled with detailed chemical kinetics, Combust. Flame. 149 (2007) 2-24.

[65] J.C.G. Andrae, Development of a detailed kinetic model for gasoline surrogate fuels, Fuel. 87 (2008) 2013-2022.

[66] J.A. Badra, N. Bokhumseen, N. Mulla, S.M. Sarathy, A. Farooq, G. Kalghatgi, P. Gaillard, A methodology to relate octane numbers of binary and ternary $n$-heptane, iso-octane and toluene mixtures with simulated ignition delay times, Fuel. 160 (2015) 458-469.

[67] G. Kalghatgi, H. Babiker, J. Badra, A Simple Method to Predict Knock Using Toluene, N-Heptane and Iso-Octane Blends (TPRF) as Gasoline Surrogates, SAE Int. J. Engines. 8 (2015) 2015-01-0757.

[68] C. V Naik, W.J. Pitz, C.K. Westbrook, M. Sjöberg, J.E. Dec, J. Orme, H.J. Curran, J.M. Simmie, Detailed Chemical Kinetic Modeling of Surrogate Fuels for Gasoline and Application to an $\mathrm{HCCl}$ 
[Type text]

Engine, in: 2005.

[69] S.M. Sarathy, G. Kukkadapu, M. Mehl, T. Javed, A. Ahmed, N. Naser, A. Tekawade, G. Kosiba, M. AlAbbad, E. Singh, S. Park, M. Al Rashidi, S.H. Chung, W.L. Roberts, M. a. Oehlschlaeger, C.-J. Sung, A. Farooq, Compositional effects on the ignition of FACE gasolines, Combust. Flame. 169 (2016) 171-193.

[70] C. Kostecka, Keith, Rabah, Ashraf, Palmer, GC/MS Analysis of the Aromatic Composition of Gasoline, J. Chem. Educ. 72 (1995) 9-10.

[71] H. Yang, Z. Ring, Y. Briker, N. McLean, W. Friesen, C. Fairbridge, Neural network prediction of cetane number and density of diesel fuel from its chemical composition determined by LC and GC-MS, Fuel. 81 (2002) 65-74.

[72] P. Ghosh, S.B. Jaffe, Detailed Composition-Based Model for Predicting the Cetane Number of Diesel Fuels, Ind. Eng. Chem. Res. 45 (2006) 346-351.

[73] S. Corsetti, F.M. Zehentbauer, D. McGloin, J. Kiefer, Characterization of gasoline/ethanol blends by infrared and excess infrared spectroscopy, Fuel. 141 (2015) 136-142.

[74] S. Corsetti, D. McGloin, J. Kiefer, Comparison of Raman and IR spectroscopy for quantitative analysis of gasoline/ethanol blends, Fuel. 166 (2016) 488-494.

[75] V.R. Ante Jukic, Sime Ukic,Bolanca, Tomislav, Slavica Marinovic, Development of Artificial Neural Network Model for Diesel Fuel Properties prediction using vibrational spectroscopy, Acta Chim.Slov. 59 (2012) 249-257.

[76] F. Chainet, J. Ponthus, C.P. Lienemann, M. Courtiade, O.F.X. Donard, Combining fourier transform-ion cyclotron resonance/mass spectrometry analysis and kendrick plots for silicon speciation and molecular characterization in petroleum products at trace levels, Anal. Chem. 84 (2012) 3998-4005.

[77] A.M. Elbaz, A. Gani, N. Hourani, A.-H. Emwas, S.M. Sarathy, W.L. Roberts, TG/DTG, FT-ICR Mass Spectrometry, and NMR Spectroscopy Study of Heavy Fuel Oil, Energy \& Fuels. 29 (2015) 78257835.

[78] A.G. Abdul Jameel, Y. Han, O. Brignoli, S. Telalović, A.M. Elbaz, H.G. Im, W.L. Roberts, S.M. Sarathy, Heavy fuel oil pyrolysis and combustion: Kinetics and evolved gases investigated by TGAFTIR, J. Anal. Appl. Pyrolysis. 127 (2017) 183-195.

[79] R. Palani, A. AbdulGani, N. Balasubramanian, Treatment of Tannery Effluent Using a Rotating Disc Electrochemical Reactor, Water Environ. Res. 89 (2017) 77-85.

[80] A. Sarpal, PONA analyses of cracked gasoline by 1H NMR spectroscopy. Part II, Fuel. 80 (2001) 521-528.

[81] B. Basu, G.S. Kapur, A.S. Sarpal, R. Meusinger, A Neural Network Approach to the Prediction of Cetane Number of Diesel Fuels Using Nuclear Magnetic Resonance (NMR) Spectroscopy, Energy \& Fuels. 17 (2003) 1570-1575.

[82] F. Karsenty, S.M. Sarathy, C. Togbé, C.K. Westbrook, G. Dayma, P. Dagaut, M. Mehl, W.J. Pitz, Experimental and Kinetic Modeling Study of 3-Methylheptane in a Jet-Stirred Reactor, Energy \& Fuels. 26 (2012) 4680-4689.

[83] S.M. Sarathy, C. Yeung, C.K. Westbrook, W.J. Pitz, M. Mehl, M.J. Thomson, An experimental and kinetic modeling study of n-octane and 2-methylheptane in an opposed-flow diffusion flame, 
[Type text]

Combust. Flame. 158 (2011) 1277-1287.

[84] H. Selim, S.Y. Mohamed, A. Lucassen, N. Hansen, S.M. Sarathy, Effect of the Methyl Substitution on the Combustion of Two Methylheptane Isomers: Flame Chemistry Using Vacuum-Ultraviolet (VUV) Photoionization Mass Spectrometry, Energy \& Fuels. 29 (2015) 2696-2708.

[85] S.M. Sarathy, C.K. Westbrook, M. Mehl, W.J. Pitz, C. Togbe, P. Dagaut, H. Wang, M.A. Oehlschlaeger, U. Niemann, K. Seshadri, P.S. Veloo, C. Ji, F.N. Egolfopoulos, T. Lu, Comprehensive chemical kinetic modeling of the oxidation of 2-methylalkanes from C7 to C20, Combust. Flame. 158 (2011) 2338-2357.

[86] W. Wang, Z. Li, M.A. Oehlschlaeger, D. Healy, H.J. Curran, S.M. Sarathy, M. Mehl, W.J. Pitz, C.K. Westbrook, An experimental and modeling study of the autoignition of 3-methylheptane, Proc. Combust. Inst. 34 (2013) 335-343.

[87] F. Battin-Leclerc, Detailed chemical kinetic models for the low-temperature combustion of hydrocarbons with application to gasoline and diesel fuel surrogates, Prog. Energy Combust. Sci. 34 (2008) 440-498.

[88] S.M. Sarathy, T. Javed, F. Karsenty, A. Heufer, W. Wang, S. Park, A. Elwardany, A. Farooq, C.K. Westbrook, W.J. Pitz, M.A. Oehlschlaeger, G. Dayma, H.J. Curran, P. Dagaut, A comprehensive combustion chemistry study of 2,5-dimethylhexane, Combust. Flame. 161 (2014) 1444-1459.

[89] G. da Silva, J.W. Bozzelli, On the reactivity of methylbenzenes, Combust. Flame. 157 (2010) 21752183.

[90] A. Roubaud, O. Lemaire, R. Minetti, L.. Sochet, High pressure auto-ignition and oxidation mechanisms of o-xylene, o-ethyltoluene, and n-butylbenzene between 600 and $900 \mathrm{~K}$, Combust. Flame. 123 (2000) 561-571.

[91] A. Roubaud, R. Minetti, L.R. Sochet, Oxidation and combustion of low alkylbenzenes at high pressure: comparative reactivity and auto-ignition, Combust. Flame. 121 (2000) 535-541.

[92] O. Mannaa, M.S. Mansour, W.L. Roberts, S.H. Chung, Laminar burning velocities at elevated pressures for gasoline and gasoline surrogates associated with RON, Combust. Flame. 162 (2015) 2311-2321.

[93] T. Javed, A. Ahmed, L. Lovisotto, G. Issayev, J. Badra, S.M. Sarathy, A. Farooq, Ignition studies of two low-octane gasolines, Combust. Flame. 185 (2017) 152-159.

[94] A. Elwardany, J. Badra, J. Sim, M. Khurshid, M. Sarathy, H. Im, Modeling of Heating and Evaporation of FACE I Gasoline Fuel and its Surrogates, in: SAE Tech. Pap., 2016.

[95] O.A. Kuti, S.Y. Yang, N. Hourani, N. Naser, W.L. Roberts, S.H. Chung, S.M. Sarathy, A fundamental investigation into the relationship between lubricant composition and fuel ignition quality, Fuel. 160 (2015) 605-613.

[96] G.E. Bogin, A. Defilippo, J.Y. Chen, G. Chin, J. Luecke, M.A. Ratcliff, B.T. Zigler, A.M. Dean, Modeling the fuel spray and combustion process of the ignition quality $\operatorname{Tester}^{\mathrm{TM}}$ with KIVA-3V, Fall Tech. Meet. West. States Sect. Combust. Inst. 2009, WSS/CI 2009 Fall Meet. 1 (2009) 507528.

[97] L.J. Mendelson, Ignition quality tester characterization with pure component and conventional navy fuels, University of Maryland, 2016.

[98] G. Bogin, A.M. Dean, M. a. Ratcliff, J. Luecke, B.T. Zigler, Expanding the Experimental Capabilities 
[Type text]

of the Ignition Quality Tester for Autoigniting Fuels, SAE Int. J. Fuels Lubr. 3 (2010) 2010-01-0741.

[99] ASTM Int., Standard Test Method for Determination of Ignition Delay and Derived Cetane Number ( DCN ) of Diesel Fuel Oils by Combustion in a Constant Volume Chamber (ASTM D6890, 2013.

[100] S.Y. Yang, N. Naser, S.H. Chung, J. Cha, Effect of Temperature, Pressure and Equivalence Ratio on Ignition Delay in Ignition Quality Tester (IQT): Diesel, $\mathrm{n}$-Heptane, and iso -Octane Fuels under Low Temperature Conditions, SAE Int. J. Fuels Lubr. 8 (2015) 2015-01-9074.

[101] N. Naser, S.Y. Yang, G. Kalghatgi, S.H. Chung, Relating the octane numbers of fuels to ignition delay times measured in an ignition quality tester (IQT), Fuel. 187 (2017) 117-127.

[102] ASTM Standard D1322-12, Standard Test Method for Smoke Point of Kerosine and Aviation Turbine Fuel, ASTM Int. (2012).

[103] H.F. Calcote, D.M. Manos, Effect of molecular structure on incipient soot formation, Combust. Flame. 49 (1983) 289-304.

[104] D.B. Olson, J.C. Pickens, R.J. Gill, The effects of molecular structure on soot formation II. Diffusion flames, Combust. Flame. 62 (1985) 43-60.

[105] A. Mensch, R.J. Santoro, T.A. Litzinger, S.-Y. Lee, Sooting characteristics of surrogates for jet fuels, Combust. Flame. 157 (2010) 1097-1105.

[106] F.M. Haas, A. Qin, F.L. Dryer, "Virtual" Smoke Point Determination of Alternative Aviation Kerosenes by Threshold Sooting Index TSI) Methods, in: 50th AIAA/ASME/SAE/ASEE Jt. Propuls. Conf., American Institute of Aeronautics and Astronautics, Reston, Virginia, 2014: pp. 1-9.

[107] NIST chemistry Webbook, NIST Stand. Ref. Database Number 69. http://webbook.nist.gov (accessed November 1, 2017).

[108] J.H. Flynn, L.A. Wall, Knocking Characteristics of Pure Hydrocarbons, ASTM International, 100 Barr Harbor Drive, PO Box C700, West Conshohocken, PA 19428-2959, 1958.

[109] Y. Ra, R.D. Reitz, A combustion model for multi-component fuels using a physical surrogate group chemistry representation (PSGCR), Combust. Flame. 162 (2015) 3456-3481.

[110] J.A. Badra, J. Sim, A. Elwardany, M. Jaasim, Y. Viollet, J. Chang, A. Amer, H.G. Im, Numerical Simulations of Hollow-Cone Injection and Gasoline Compression Ignition Combustion With Naphtha Fuels, J. Energy Resour. Technol. 138 (2016) 52202.

[111] N. Atef, J. Badra, M. Jaasim, H.G. Im, S.M. Sarathy, Numerical investigation of injector geometry effects on fuel stratification in a GCl engine, Fuel. 214 (2018) 580-589.

[112] J. Badra, Y. Viollet, A. Elwardany, H.G. Im, J. Chang, Physical and chemical effects of low octane gasoline fuels on compression ignition combustion, Appl. Energy. 183 (2016) 1197-1208.

[113] N. Naser, M. Jaasim, N. Atef, S.H. Chung, H.G. Im, S.M. Sarathy, On the effects of fuel properties and injection timing in partially premixed compression ignition of low octane fuels, Fuel. 207 (2017) 373-388.

[114] P.B. Govindaraju, M. Ihme, Formulation of optimal surrogate descriptions of fuels considering sensitivities to experimental uncertainties, Combust. Flame. 188 (2018) 337-356.

[115] H. Wang, R. Xu, K. Wang, C.T. Bowman, R.K. Hasnon, D.F. Davidson, K. Brezinsky, F.N. Egolfopoulos, A Physics-based approach to modeling real-fuel combustion chemistry - I. Evidence 
[Type text]

from experiments, and thermodynamic, chemical kinetic and statistical considerations, Combust. Flame, submitted, 2017.

[116] R. Xu, K. Wang, S. Banerjee, J. Shao, T. Parise, Y. Zhu, S. Wang, A. Movaghar, D.J. Lee, R. Zhao, X. Han, Y. Gao, T. Lu, K. Brezinsky, F.N. Egolfopoulos, D.F. Davidson, R.K. Hanson, C.T. Bowman, H. Wang, A Physics-based approach to modeling real-fuel combustion chemistry - II. Reaction kinetic models of jet and rocket fuels, Combust. Flame, submitted, 2017. 
[Type text]

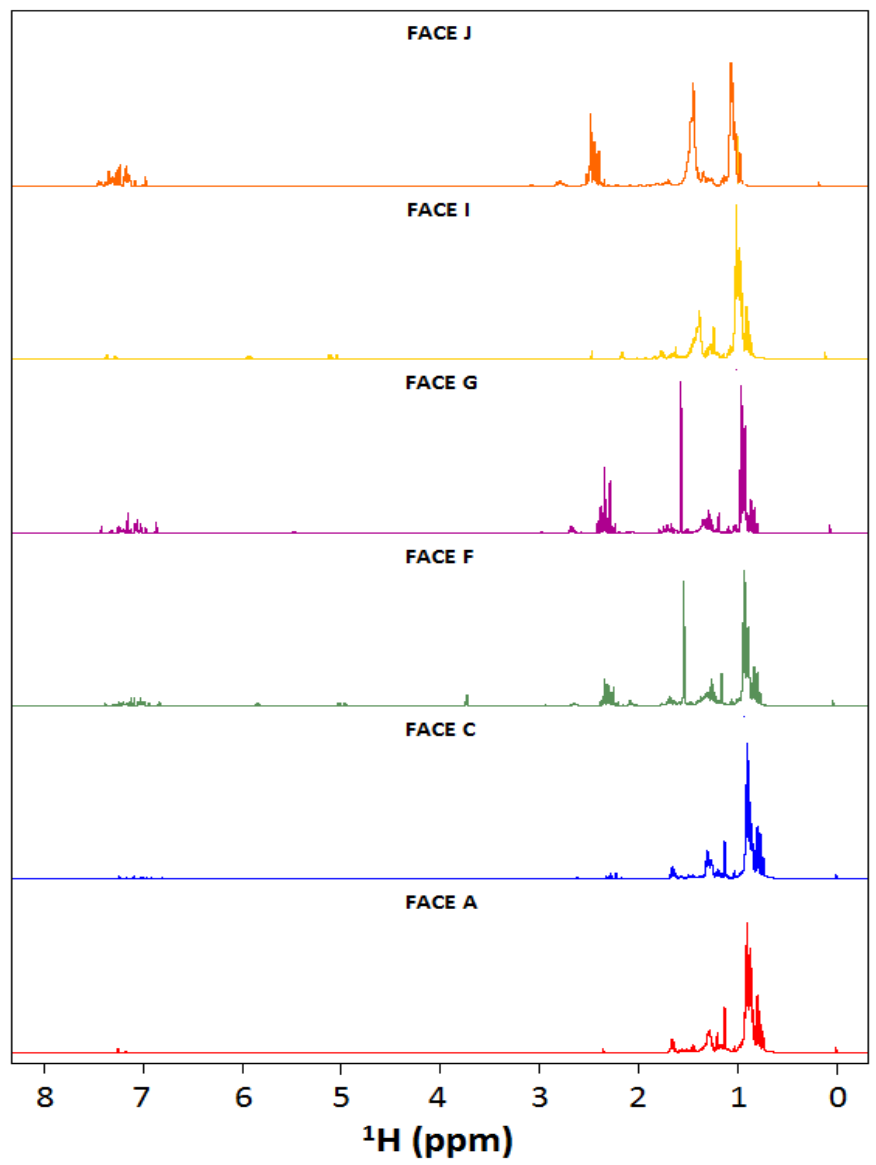

Fig. $1 .{ }^{1} \mathrm{H}$ NMR spectra of the FACE gasoline fuels 
[Type text]

FACE A

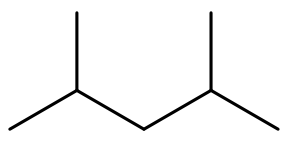

2,4-dimethylpentane $(B \mathrm{Bl}=0.4)$

FACE C

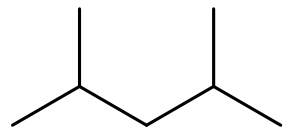

2,4-dimethylpentane $(B \mid=0.4)$

FACE F

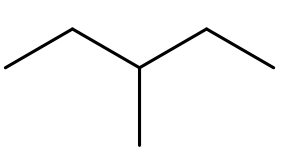

3-methylpentane $(\mathrm{BI}=0.3)$
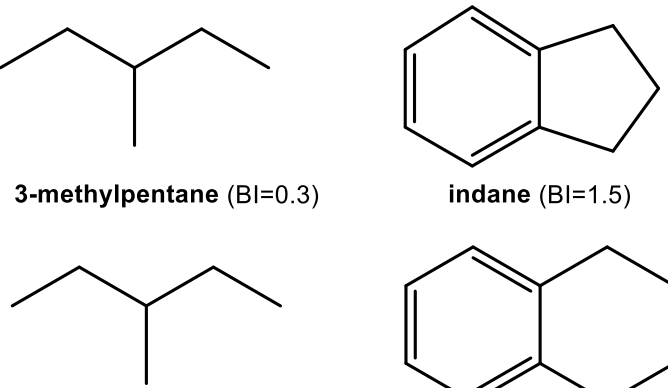

3-methylpentane $(\mathrm{BI}=0.3)$

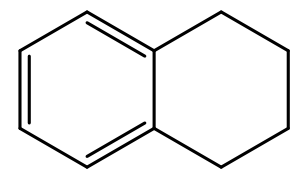

tetralin $(\mathrm{BI}=1.5)$

FACE I

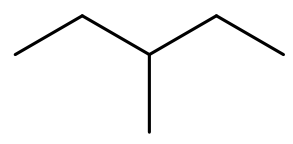

3-methylpentane $(\mathrm{BI}=0.3)$

FACE $J$

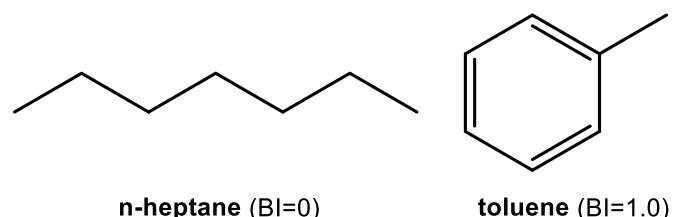

Fig. 2. Chosen surrogate molecules for the FACE gasolines. The BI for each surrogate molecule is denoted. 
[Type text]
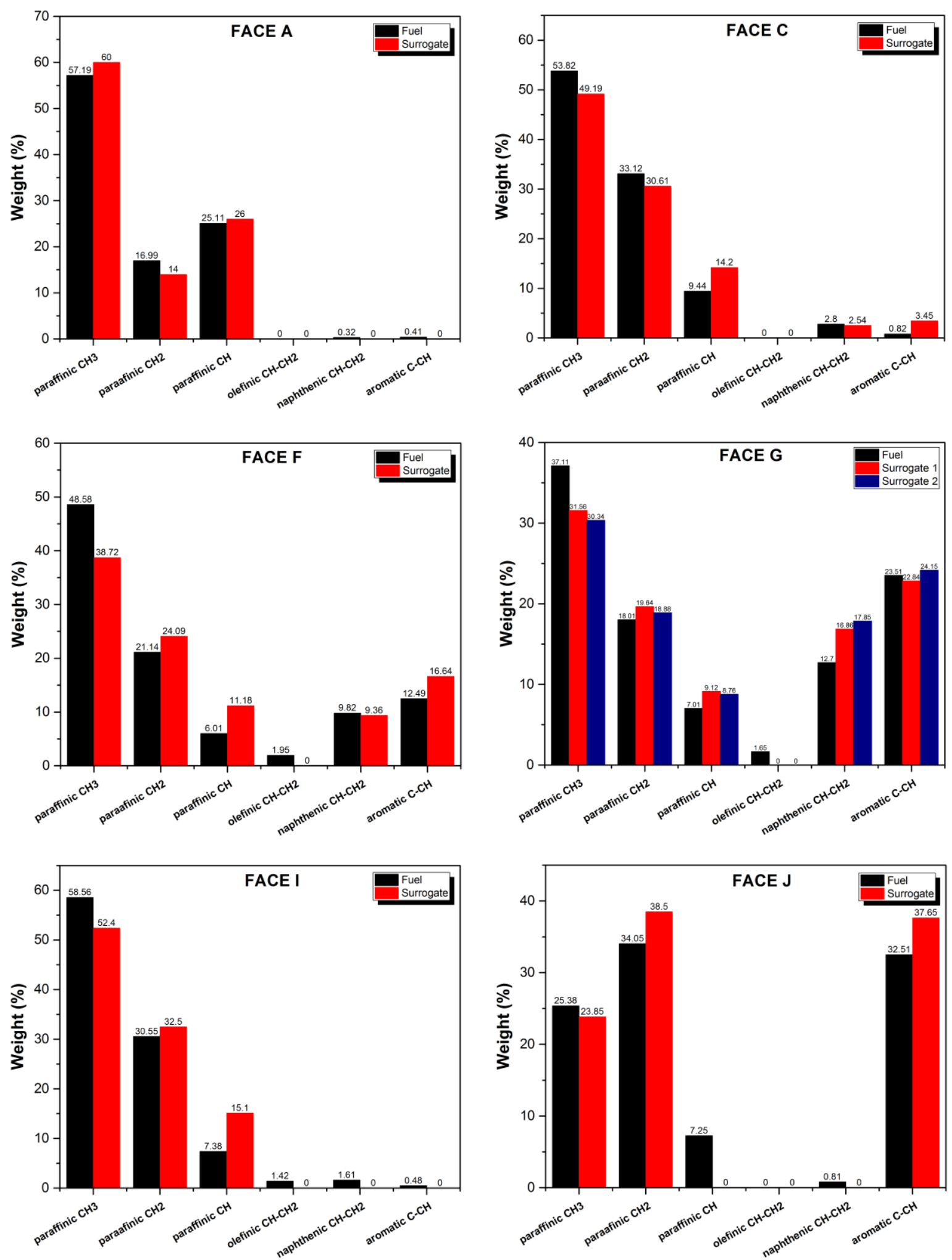

Fig. 3. Functional group comparison between the FACE gasolines and their respective MFG surrogates 
[Type text]
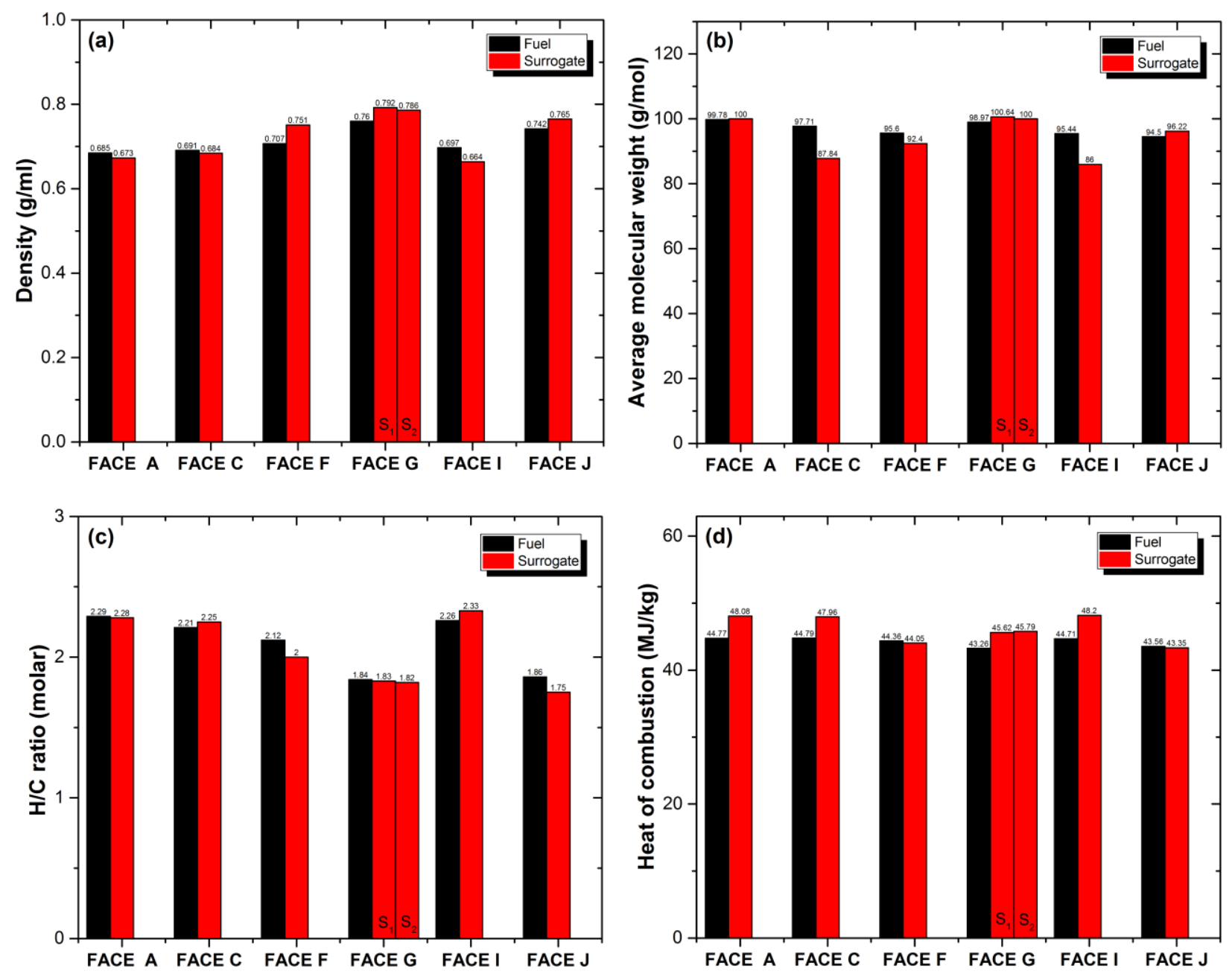

Fig. 4. Comparison of the physical and chemical properties of the FACE gasolines and their respective MFG surrogates a) density b) average molecular weight c) $\mathrm{H} / \mathrm{C}$ ratio and d) heat of combustion. $\mathrm{S}_{1}$ and $\mathrm{S}_{2}$ refer to surrogate 1 surrogate 2 , respectively. 
[Type text]
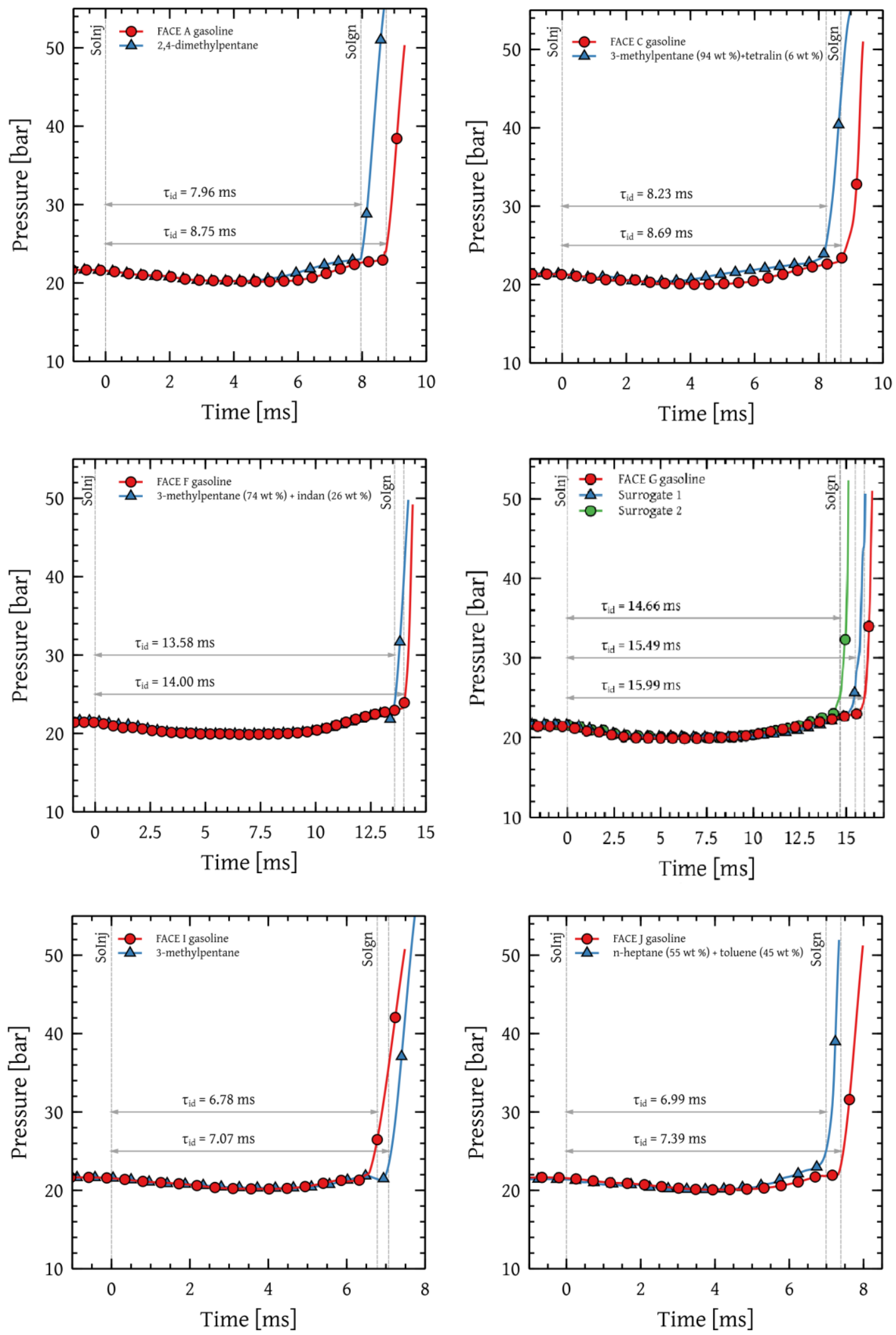

Fig. 5. Pressure traces of the FACE gasolines and their respective MFG surrogates from the IQT 

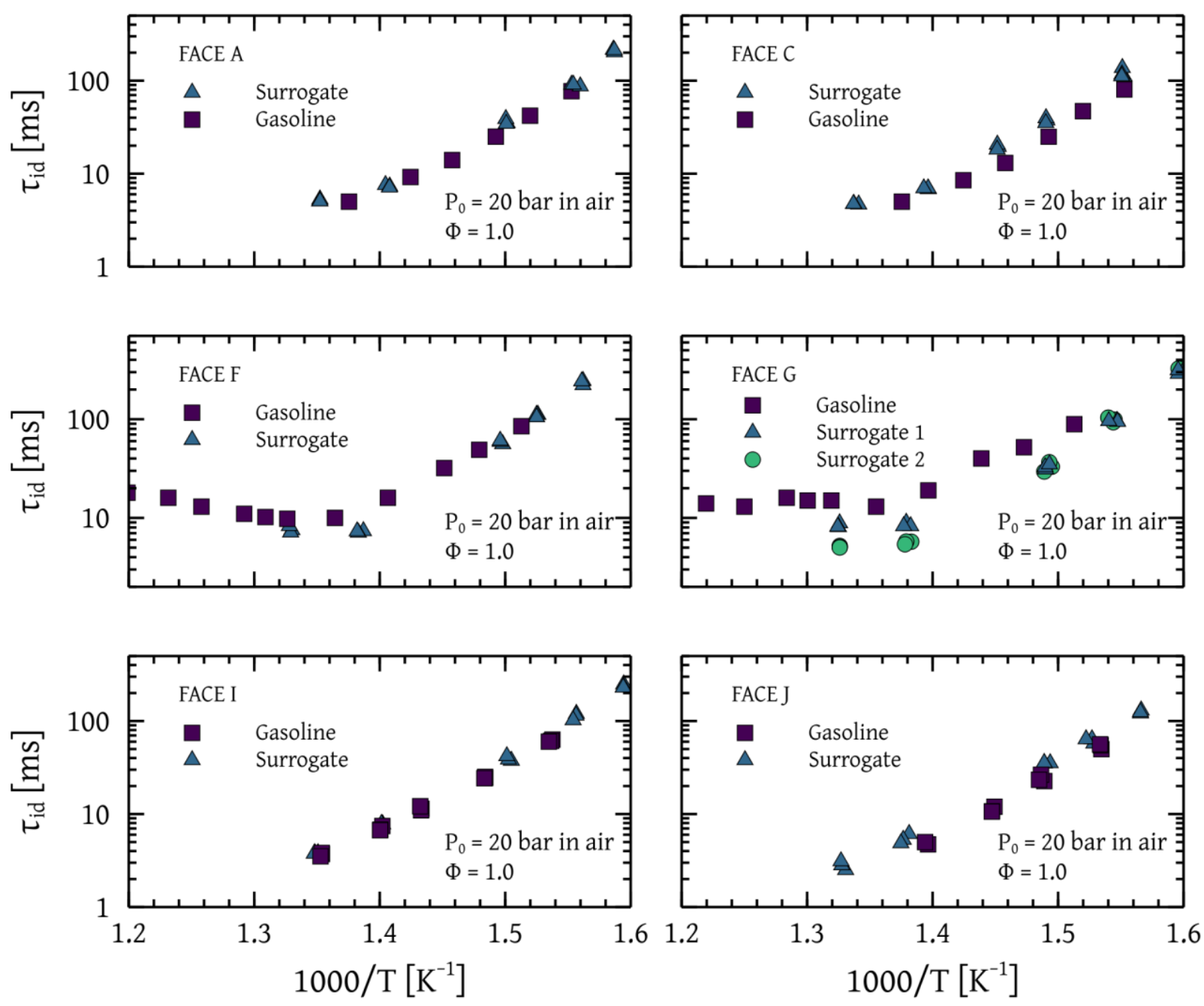

Fig. 6. Ignition delay times of the FACE gasolines and their respective MFG surrogates from RCM at a pressure of 20 bar and at stoichiometric conditions. 
[Type text]
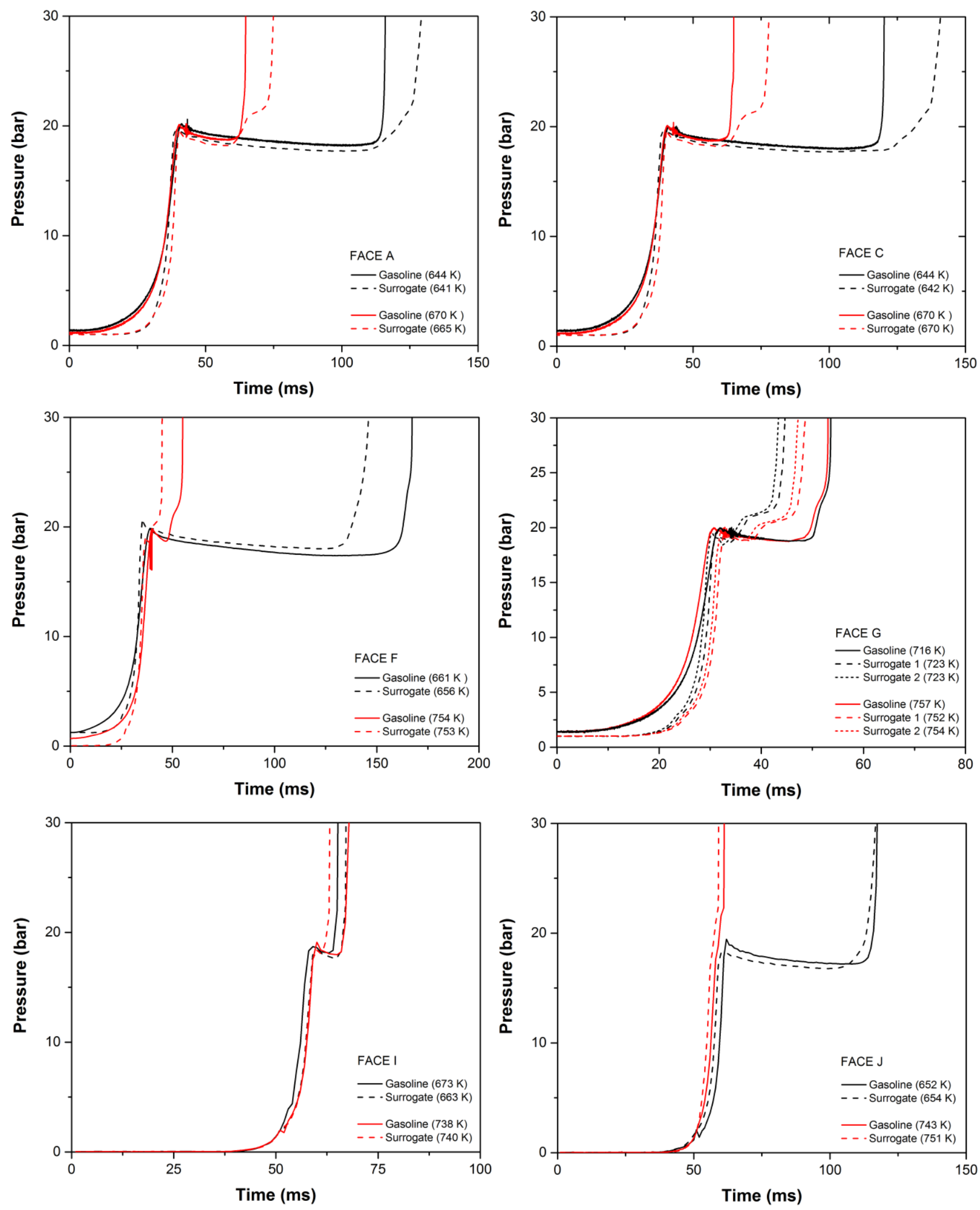

Fig. 7. Pressure traces of the FACE gasoline and their respective MFG surrogates from RCM 
FACE A

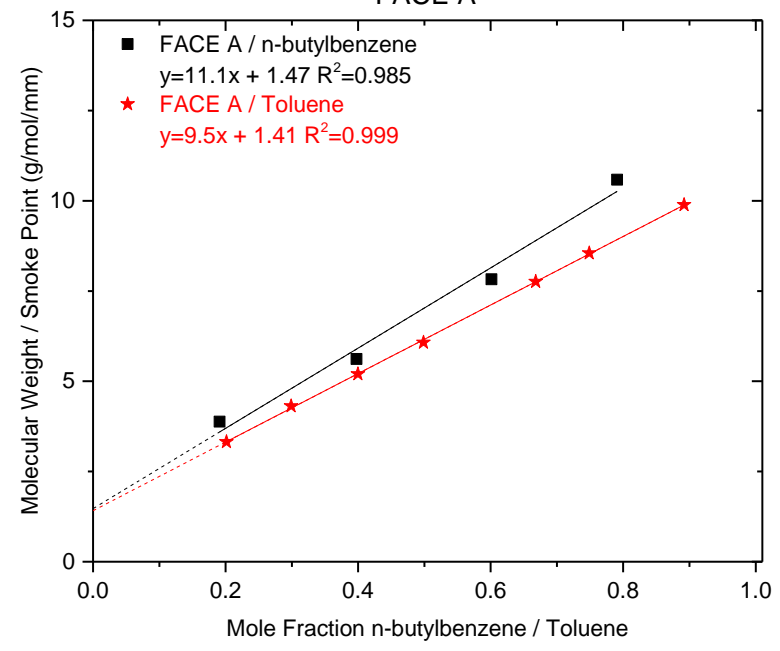

FACE C

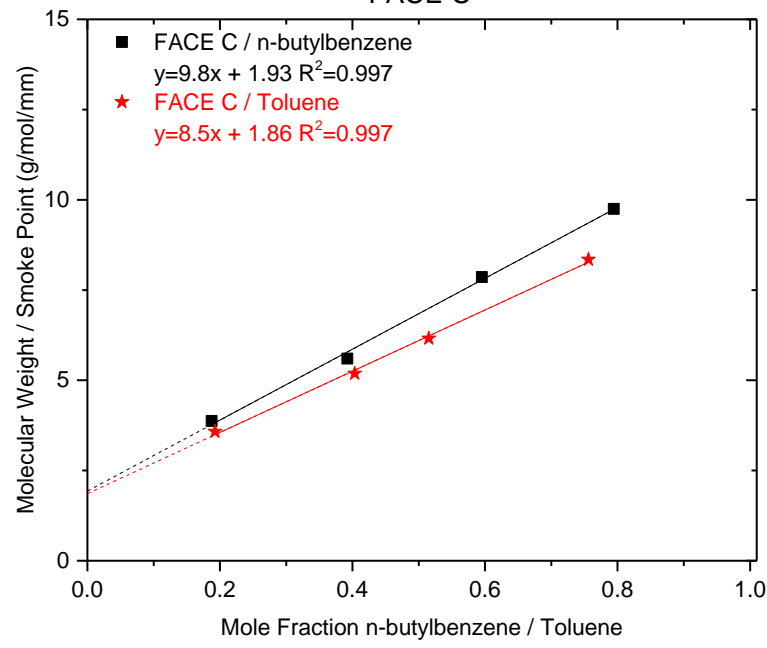

FACE I

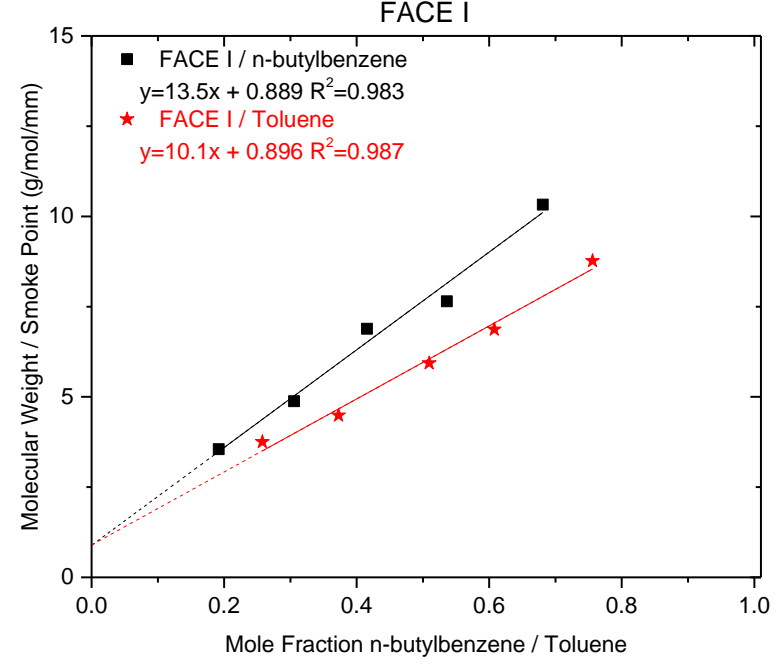

Fig. 8. Virtual smoke point determination of FACE A, C and I gasolines using n-butylbenzene and toluene as blend components. 

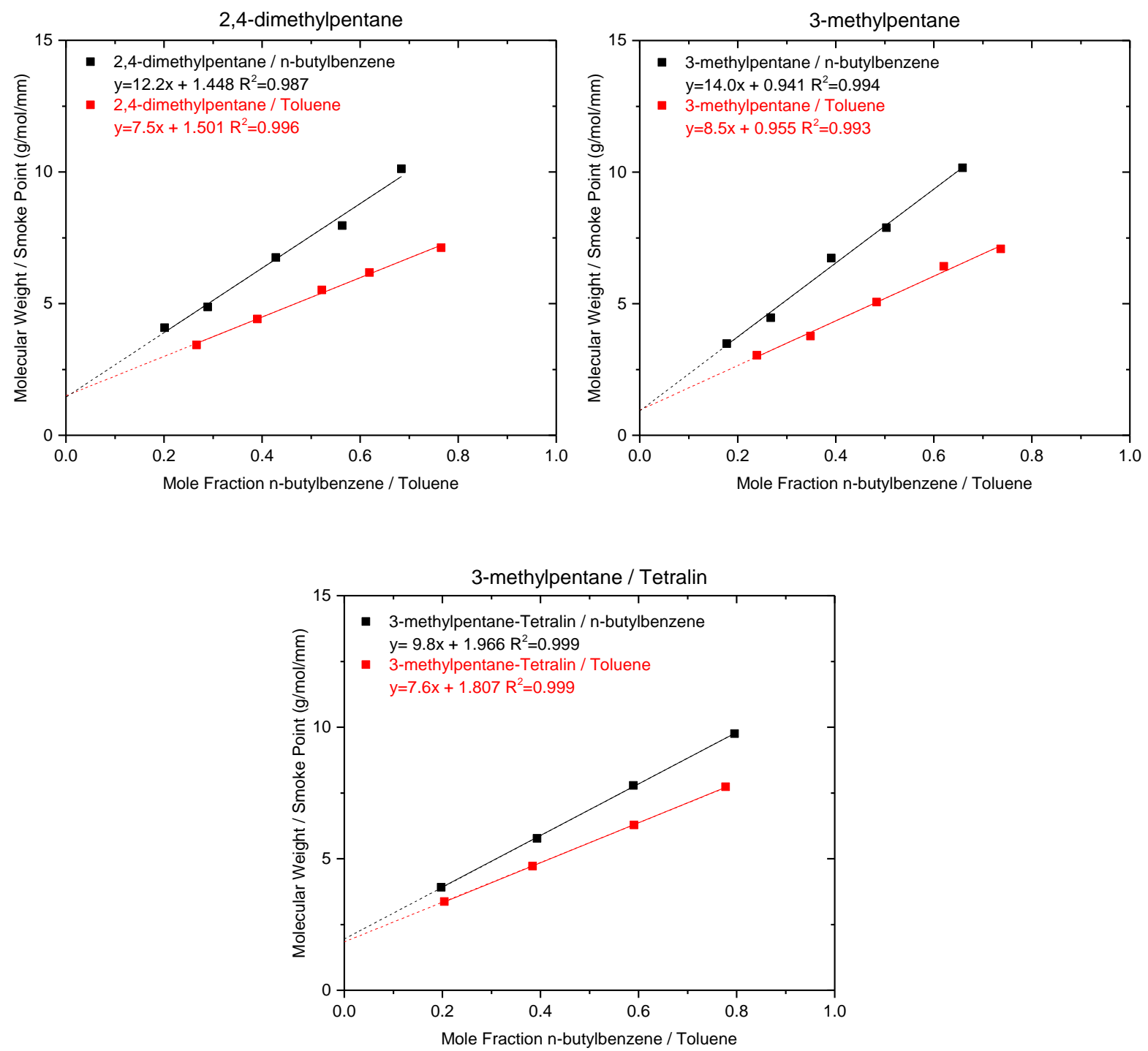

Fig. 9. Virtual smoke point determination of 2,4-dimethylpentane ( surrogate for FACE A), 3methylpentane-tetraline (surrogate FACE C) and 3-methylpentane (surrogate for FACE I) using nbutylbenzene and toluene as blend components. 
[Type text]

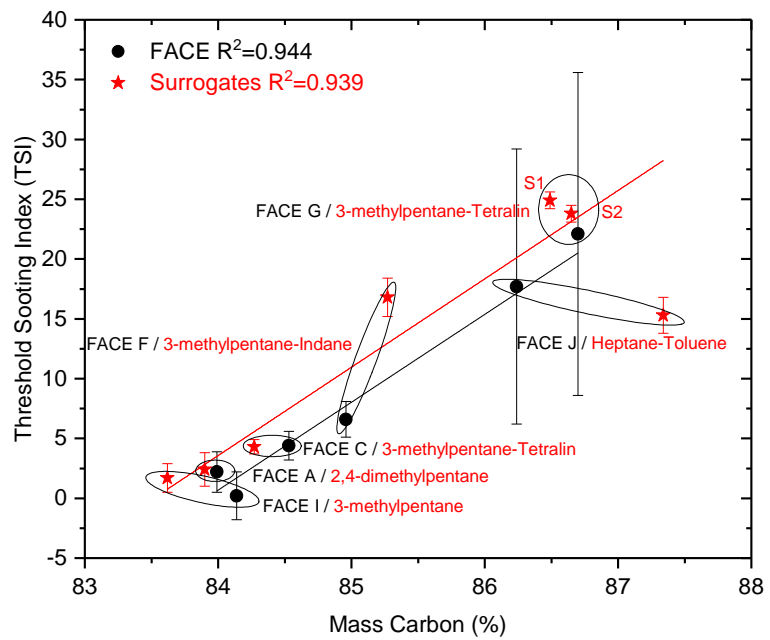

Fig. 10. Threshold Sooting Index vs Carbon Ratio of the FACE gasolines and respective MFG surrogates. 